Vermont Maple Sugar Makers Association. Proceedings of sixteenth meeting. 1909.

Croft, A. J. President's address.

Seary, G. C. Maple products from view points of the producer and the consumers.

Sherbourne, A. E. Improved methods in making maple sugar as an article of luxury.

Spear, V. I. Maple sugar industry.

Proceedings of seventeenth meeting. 1910.

Croft, A. J. President's address.

Edson, H. A. Micro-organisms in maple sirup.

Hawes, A. F. Forestry.

Hayes, J. R. One man's experience in making maple sirup and sugar.

Spear, V. I. What the maple sugar makers' market has been doing in the past year.

Thomas, M. C. The past, present, and future of the maple sugar industry.

o 
U. S. DEPARTMENT OF AGRICULTURE, BUREAU OF CHEMISTRY-BULLETIN No. 135.

H. W. WILEY, Chief of Bureau.

\title{
COMMERCIAL TURPENTINES:
}

\section{THEIR QUALITY AND METHODS}

FOR THEIR EXAMINATION.

\author{
BY \\ F. P. VEITCH, \\ Chief, Leather and Paper Laboratory, \\ AND \\ M. G. DONK, \\ Assistant Chemist.
}

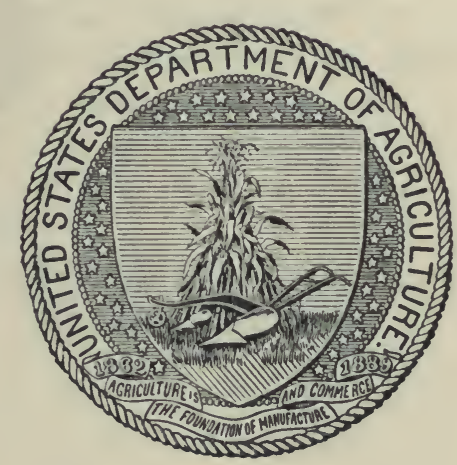

WASHINGTON :

GOVERNMENT PRINTING OFFICE. 


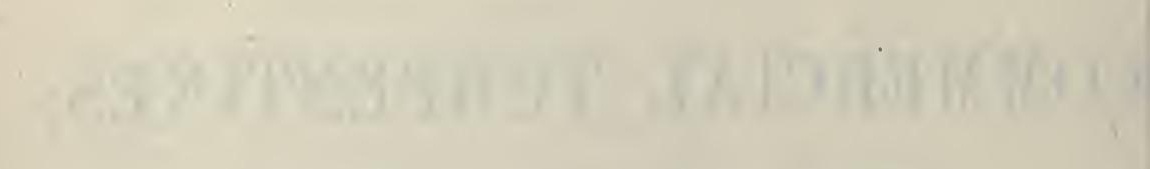




\section{LETTER OF TRANSMITTAL.}

\section{U. S. Department of Agriculture, Bureau of Chemistry, Washington, D. C., October 15, 1910.}

SIR: I beg to submit for your inspection and approval the results btained in an investigation made in this Bureau by F. P. Veitch and M. G. Donk on the adulteration and grading of turpentines. The results show the extent to which turpentine is adulterated, and ndicate the loss of values to the turpentine farmers, and the extent o which turpentine users are defrauded by adulteration. Methods or the analysis and testing of turpentine have been simplified and mproved. Based largely on this investigation and the field work connected therewith, specifications for grades are suggested which $t$ is believed will prove equitable to the producer and enable the ourchaser to secure turpentine of the character desired. The data btained are thus of special interest to the buyers and sellers of this oroduct. I recommend that this report be published as Bulletin No. 135 of the Bureau of Chemistry

Respectfully,

Hon. James Wilson,
H. W. WILEY, Chief of Bureau.

$$
\text { Secretary of Agriculture. }
$$


Digitized by the Internet Archive in 2007 with funding from Microsoft Corporation 


\section{ILLUSTRATION.}

Frg. 1. Apparatus for the fractional distillation of turpentine............. 


\section{COMMERCIAL TURPENTINES.}

\section{INTRODUCTION.}

NATURE AND GENERAL PROPERTIES.

Commercial spirits of turpentine is a mixture of similar and closely related terpenes having the general composition expressed by the formula $\mathrm{C}_{10} \mathrm{H}_{10}$, with varying quantities of oxidized and hydrated derivatives of terpenes, usually present only in small amounts when first distilled from the gum.

These terpenes differ both in their physical and chemical properties, and consequently commercial turpentine may distill at from $154^{\circ}$ to $215^{\circ} \mathrm{C}$. $\left(309^{\circ}\right.$ to $419^{\circ} \mathrm{F}$.). The fractions obtained on distillation have specific gravities ranging from 0.8580 to 0.9500 or more, with refractive indices of from 1.462 to 1.520 , respectively.

The pinenes, several of which, differing slightly from one another in boiling point, specific gravity, and refractive index, have been recognized, are among the chief constituents of spirits of turpentine freshly distilled from the gum. Dipentene ${ }^{1}$ has also been reported as occurring in American turpentine, but as dipentene distills alone at about $178^{\circ} \mathrm{C}$, it is probably present in but small quantities in those turpentines which distill completely below this temperature. The above-mentioned terpenes boil between $155^{\circ} \mathrm{C}$. $\left(311^{\circ} \mathrm{F}\right.$.) and $178^{\circ} \mathrm{C}$. $\left(352^{\circ} \mathrm{F}\right.$.) ; their specific gravities lie between 0.845 and 0.866 , and their refractive indices between 1.46 and 1.472 . Other constituents which may be present, regarding the identity of which but little is known, have specific gravities of from 0.865 to 0.950 and refractive indices as high as 1.5200 at $20^{\circ} \mathrm{C}$., and boil at from $160^{\circ} \mathrm{C}$. to $215^{\circ} \mathrm{C}$. $\left(320^{\circ}\right.$ to $419^{\circ} \mathrm{F}$.). Turpentines which have been kept long, particularly those held in partly filled vessels, frequently have higher specific gravities, refractive indices, and boiling points than freshly distilled turpentine. In changing they become more oily and usually somewhat darker in color.

The quantity of each constituent present in commercial American turpentine is influenced not only by the physiological processes of the individual trees, but also, and probably more largely, by the

1 Gildemeister, Die Aetberiscbe Oele, 2d ed., 1910, p. 328; Allen, Commercial Organic Analysis, 3d ed., vol. 2, pt. 3, p. 263. 
conditions under which the crude gum is gathered and the time which elapses before it is distilled, by the method of conducting the distillation, and finally by subsequent storage conditions. When the face of the tree over which the crude gum flows before it reaches the box is long, the weather hot, and the gum is kept long before it is distilled, there is more evaporation of the lighter constituents and at the same time the oxidation and polymerization of the gum are increased. It is customary to carry the distillation further on gum from old than from new boxes. The temperature in the final stages of the distillation rises higher, as a rule, and the product obtained near the close of the distillation is more frequently colored or burned. For these reasons turpentine from old boxes, as a rule, is heavier, distills less completely below $170^{\circ} \mathrm{C}$., and has a higher refractive index than turpentine made from first-year gum or "virgin dip."

One of the chief causes of the observed variations in the constants of turpentine freshly distilled from the gum lies in the practice followed in the barreling of the product at the still. From time to time during the distillation the turpentine is transferred to barrels for shipment, and as a rule the turpentine first distilled is placed in one barrel, the middle portion in another, and the last off in a third barrel. In the earlier stages of the distillation the turpentine having the lowest specific gravity, refractive index, and distilling temperature passes over. As distillation proceeds the distillation temperature, gravity, and refractive index of the distilling turpentine steadily increase, though with occasional lapses and not necessarily proportionally. As a result the constants of the turpentine in the first barrel may agree with the lower limits, while that in the last barrel may approach the upper limits recognized for turpentine.

Because of these conditions, exposure in the woods, variations in distilling, differences in the product at successive stages of the distillation, and changes in composition after distillation, it is customary to recognize variations in the specific gravity of turpentine from 0.862 to 0.875 , in refractive index from. 1.4670 to 1.4750 , both at $15.5^{\circ} \mathrm{C}$., and in the initial boiling point of from $154^{\circ} \mathrm{C}$. to $159^{\circ}$ C. $\left(309^{\circ}\right.$ to $318^{\circ} \mathrm{F}$.), while the percentage which distills below $170^{\circ}$ C. $\left(338^{\circ} \mathrm{F}\right.$.) varies from about 85 to 99 per cent.

Old turpentine, even though it is kept in closed vessels, may undergo changes and have a specific gravity as high as 0.9460 and a refractive index of 1.480 or more, while the initial boiling point is raised and the percentage distilling below $170^{\circ} \mathrm{C} .\left(338^{\circ} \mathrm{F}\right.$.) is lowered.

It is desired in this bulletin to distinguish between old turpentine and turpentine to which mineral, coal tar, or other dissimilar oils have been added. While old, highly oxidized turpentines can not properly be classed as normal turpentines, they are, nevertheless, 
mixtures of terpenes and related heavier oils and as such may possess the peculiar properties which are commercial assets of turpentine and which distinguish it sharply from unrelated oils which are often substituted wholly for it or employed in its sophistication. In the one case the product is a natural result of aging, while in the other it may properly be said to be adulterated, and such oils will be so distinguished in this publication.

\section{SOURCES AND METHODS OF PRODUCTION.}

Oil or spirits of turpentine, commonly known as "turpentine," or in the paint trade simply as "turps," is obtained chiefly from the longleaf pine (Pinus palustris), though a portion is also obtained from Cuban ( $P$. heterophylla) and a little from loblolly pine ( $P$. $t æ d a)$. The Forest Service has found that loblolly, shortleaf, and Virginia pines yield naval stores equal in quantity to the longleaf yellow pines, and as the former occur in large quantities in the South their utilization would add largely to the turpentine resources of the country.

During the winter months before the sap begins to rise a pocket or "box" is cut in the tree near the ground, and at intervals during the succeeding spring and summer the bark and a portion of the sap wood are removed from the trunk above the box. This cutting greatly shortens the life of the tree and renders it more liable to destruction by wind, storm, and fire. The injury to standing timber caused by turpentining may be largely avoided by collecting in cups, the gum being directed into them by strips of zinc or heavily galvanized iron set in the face of the tree. This system, used exclusively in France, is now being extensively introduced in a modified form into this country and not only protects the tree but, as has been shown by the Forest Service, yields a higher grade of rosin and more turpentine.

In the spring the crude gum begins to flow from the "face," as that portion of the tree from which the bark and a part of the sapwood have been removed is called, and collects in the box or cup near the base, from which it is removed by dipping from time to time during the flowing season, which lasts from March to October or later. The thick, resinous mass, which usually contains water, chips, bark, pine needles, earth, and charred wood, is taken to the still, which is a large copper kettle with an outlet in the bottom by means of which it may be emptied and a cap connecting with a condensing coil. The kettle is bricked around in order that it may be safely heated by a fire underneath.

The crude gum is poured into the kettle until it is from one-third to one-half full and then slowly heated. A portion of the chips, bark, and pine needles is skimmed out after the contents of the kettle $72457^{\circ}-$ Bull. 135-11-2 
become thoroughly liquid, and the cap is replaced in position and connected with the condenser while the heating of the kettle is slowly continued. Slow, cautious heating is made necessary by the presence of water in the gum, which causes frothing when the gum begins to boil, and if the heating is unduly hastened the gum will froth over, causing loss and delay. The presence of water in the gum lowers the boiling point of the mixture, so that both turpentine and water begin to distill at about $94^{\circ}$ to $95^{\circ} \mathrm{C}$. $\left(201^{\circ}\right.$ to $203^{\circ} \mathrm{F}$.) ; alone it distills at from $155^{\circ}$ to $170^{\circ} \mathrm{C}$. $\left(311^{\circ}\right.$ to $338^{\circ} \mathrm{F}$.).

When the danger of frothing over has passed, which means usually that most of the water has boiled off, a small stream of water is allowed to run into the still through the cap, as in this way the distillation is conducted at a much lower temperature than would otherwise be possible.

The condensed turpentine and water are collected in a separator, where the turpentine collects on top and may be drawn off from time to time. The separated spirits of turpentine is then run into tight white-oak barrels, which have been well driven and glued to prevent the turpentine soaking through the wood. The barrels are filled to within 1 gallon of their capacity, leaving room for expansion of the turpentine, which takes place with a rise of temperature and would cause leakage if the barrel were filled at the ordinary temperature. The barreled turpentine is then ready for the market.

The residue in the kettle from the turpentine distillation is rosin, which while still hot is run out of the opening in the bottom through wire screens and then strained through cotton cloth or batting to remove the remaining chips, straw, and dirt, after which it is barreled and cooled.

When distillation is properly conducted with water all of the turpentine distills below $150^{\circ}-160^{\circ} \mathrm{C}$. $\left(302^{\circ}-320^{\circ} \mathrm{F}\right.$.), and there is little apparent breaking up of rosin or discoloration of the turpentine. If the temperature is allowed to rise above $160^{\circ}-170^{\circ} \mathrm{C}$. $\left(320^{\circ}-338^{\circ}\right.$ F.) toward the end or the distillation is prolonged, or if water is not used in distillation, both the turpentine and the rosin are darker colored.

The color of turpentine is due primarily to overheating the gum and possibly partly to the chips, pine straw, etc., left in the kettle during the distillation. Wood begins to color decidedly above $150^{\circ}$ C. $\left(302^{\circ} \mathrm{F}\right.$.), so that it is almost impossible to make a colorless rosin if there are any chips or bark in the still. Prolonged heating of the rosin at $130^{\circ} \mathrm{C}$. will lower the color several grades. Hence, to make turpentine and rosin having but little color the gum should be free of wood, bark, and pine straw, the contents of the still should never rise above $160^{\circ} \mathrm{C}$. at any point, and the distillation should be conducted as rapidly as is practicable. 
In the past but few stills were equipped with thermometers to indicate the temperature of the gum in the still, but it is probable that in properly conducted distillation the temperature rarely rose above $170^{\circ} \mathrm{C}$., and for virgin gum was considerably lower than this. Thermometers are coming into more general use in turpentine distilling, and the danger from overheating is being correspondingly reduced.

DISTRIBUTION, QUANTITY PRODUCED, AND VALUE.

The turpentine-producing area in this country is practically confined to the coastal plains region of the Southern States. In the earlier days the industry was best developed in North Carolina, but owing to destructive methods of turpentine orcharding, in conjunction with lumbering, fires, etc., the industry has gradually worked southward and westward, until at present Florida produces the most turpentine, followed by Georgia, Alabama, Mississippi, Louisiana, North Carolina, South Carolina, and Texas, in the order named.

The statistics of the production for the past 40 years taken from the census reports are given in the following table:

Turpentine production in the United States for the past 40 years.

\begin{tabular}{|c|c|c|}
\hline Year. & Gallons. & Value. \\
\hline 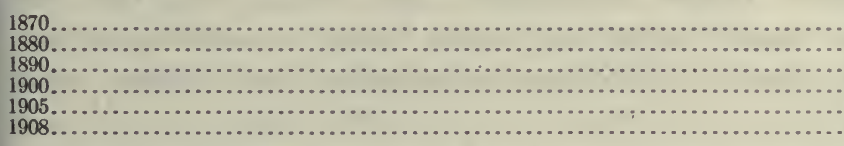 & $\begin{array}{r}6,004,887 \\
17,565,250 \\
17,316,200 \\
38,488,170 \\
30,687,051 \\
36,589,000\end{array}$ & $\begin{array}{r}\$ 2,194,498 \\
1,542,120 \\
5,459,115 \\
14,960,235 \\
15,170,499 \\
14,112,400\end{array}$ \\
\hline
\end{tabular}

GRADING, MARKETING, AND USES.

It is the trade practice to grade turpentine according to its color, and the various grades are known as "water white," "standard," "off one shade," "off two shades," and "off three shades." The latter is not merchantable. Under the trade regulations the deduction in price on turpentine off one shade is 2.5 cents per gallon and off two shades 4 cents per gallon. Of late years, however, it has become customary to mix the colored turpentine with water-white or standard turpentine, adding a small quantity to each barrel which is not full. The factor is paid 50 cents for each barrel of the colored turpentine that he uses in this way. By this practice the producer receives more for his colored turpentine than he otherwise would under the trade regulations, and but one grade of turpentine is generally known to the buyer beyond the primary markets. There are, however, as has been indicated in the discussion on general properties and methods of production, decided differences in the 
quality of various lots of turpentine. Recognizing this fact many users of large quantities buy on definite and rather strict specifications, and it would probably be of advantage to the trade if several grades for turpentine were more generally recognized.

About half of the turpentine produced in this country each year is exported, chiefly to Europe, while by far the larger part of the remainder is consumed in the varnish and paint industries, and small quantities are used in medicine and as a solvent for gums, rubber, fat, and waxes, in this country. No statistics are obtainable showing the quantities consumed for the latter purposes, nor in thinning paints and varnishes at the time they are actually used. The distribution of turpentine produced in $1905^{1}$ was as follows:

Gallons.

Produced

$30,687,051$

Exported

$15,894,813$

Used in manufacture of paints and varnishes

$7,160,774$

Used in medicine, and as a solvent in other industries and for paint and

varnish thinning, etc. (by difference)..................... $7,631,464$

\section{COLLECTION AND CLASSIFICATION OF SAMPLES.}

The turpentine found on the American market is quite frequently adulterated with cheaper and inferior oils, those most commonly employed being the petroleum oils having specific gravities corresponding closely to that of turpentine, and distilling at about the same temperature. Other adulterants are certain coal-tar oils, rosin spirits, and wood turpentine, which closely resemble turpentine in specific gravity, distilling temperature, and some other properties.

Work on turpentines found on the American market was undertaken under the Food and Drugs Act of June 30, 1906, for the primary purpose of determining the nature and extent of adulteration in turpentine sold for medicinal purposes. Furthermore, it is desirable to know at what stage in the marketing of this article it is generally adulterated. The naval stores industry is vitally interested in the matter, as the value of the turpentine output is materially affected by the practice of adulteration. It is quite common for druggists, both wholesale and retail, to buy turpentine from oil and paint dealers or from anyone handling it in large quantities, and, therefore, samples have been secured from oil and paint dealers, as well as from druggists, their stock being in many instances representative of the turpentine sold at the drug stores in the same community. In fact rarely is any distinction made between turpentines for drug or technical purposes.

Though it is known that spirits of turpentine is very frequently adulterated, no systematic investigation of the subject in this 
country is on record. For this reason, the results obtained on samples collected from all parts of the country are recorded for the information of the public, to show the extent of the practice of adulteration, and to furnish more complete data for the grading of American turpentine and the preparation of specifications therefor which shall be fair to the producer and also insure that the consumer secures the article for which he pays.

The samples have been classified into those secured within and without the turpentine-producing States, and each of these classes has been subdivided into three groups. First, samples taken from the producer, or in the yards of primary buyers, but which the primary buyers stated, and the evidence indicated, were in the original containers in exactly the condition in which they were received from the producer. Second, samples taken from the tanks or other containers of primary buyers after they had accepted the goods from the producers. Third, samples taken from the stock of wholesale and retail druggists, paint and hardware merchants, and other dealers. These classifications are made to show as clearly as possible at what point in the turpentine industry adulteration is most practiced.

\section{METHODS OF ANALYSIS EMPLOYED AND THEIR DISCUSSION.}

\section{GENERAL EXAMINATION.}

Owing to the nature of turpentine, there are quite wide variations in its chemical and physical constants, and as these natural variations do not appear within limits to affect its suitability for technical and medicinal purposes, rigid control of analytical procedure usually is not insisted upon in the examination of the article, and, indeed, great refinement of procedure is scarcely warranted. Thus specific gravity and refractive index need not be expressed beyond the third decimal, flash point and distilling temperature should be stated in whole degrees, while the residues from polymerization and the results of distillation should be given in whole numbers as percentage. For these reasons, and in order that the results might be comparable with other published data, the usual procedure in the examination of turpentine has been followed in the main in analyzing the samples reported in this bulletin. It became apparent, however, as the work progressed that certain precautions and modifications in making such examinations were desirable in order that concordant results might be obtained by different analysts, and conditions affecting the results on adulterated and certain oxydized samples be better controlled. The details of the modified methods are given, beginning on page 26 . 
The methods as applied to the samples analyzed in this investigation are as follows:

Specific gravity was determined with the Westphal balance at $20^{\circ} \mathrm{C}$.

Refractive index was determined at $20^{\circ} \mathrm{C}$. with the Zeiss refractometer.

Color was determined by means of the Lovibond colorimeter, and is, for simplicity of standardization, expressed in terms of the depth in millimeters of the liquid which gives a color equal to the Lovibond tintometer glass No. 1 yellow.

Distillation.-One hundred and fifty cubic centimeters of turpentine were put in a $200 \mathrm{cc}$ flask having a neck $20 \mathrm{~mm}$ in diameter and the side tube $10 \mathrm{~cm}$ from the bulb. The bulb of an accurate thermometer was placed opposite the side tube, the flask set in a glycerin or oil bath, connected with condenser, heated, and distillation conducted at the rate of two drops per second.

The results obtained on the commercial samples have not been corrected for the emergent stem of the thermometer, and for this reason the recorded readings are on the average, by actual comparison, about $3.5^{\circ}$ lower, and as a maximum on the higher boiling fractions, about $6^{\circ}$ lower, than the actual temperatures. Neither has correction been made for variation in barometric pressure. The most serious consequence of not making these corrections is found in determining the exact initial distilling point and the percentage of turpentine distilling at successive temperatures. As a matter of fact, these corrections would have but little effect in the case of a normal turpentine on the total percentage distilling below the upper limit for turpentine, which may very properly, as the work indicates, be put at $170^{\circ}$, when the reading is taken with the scale of the thermometer entirely within the neck of the distilling flask.

\section{EFFECT OF EMERGENT THERMOMETER.}

The differences in temperature readings, due to emergent stem, and the effect of these differences on the quantity of turpentine distilled at various temperatures as determined by actual comparisons, are shown in the following table. In all cases the bulbs of the thermometer were opposite the side neck of the flask. 
Comparison of differences of temperature and of volumes distilled, due to emergent stem of thermometer.

[200 cc of turpentine distilled.]

\begin{tabular}{|c|c|c|c|c|c|c|c|}
\hline \multicolumn{4}{|c|}{ Turpentine No. 1.} & \multicolumn{4}{|c|}{ Turpentine No. 2.} \\
\hline \multicolumn{2}{|c|}{$\begin{array}{l}\text { Reading of thermom- } \\
\text { eter- }\end{array}$} & \multirow{2}{*}{ Difference. } & \multirow{2}{*}{$\begin{array}{l}\text { Volume } \\
\text { distilied. }\end{array}$} & \multicolumn{2}{|c|}{$\begin{array}{c}\text { Reading of thermom- } \\
\text { eter- }\end{array}$} & \multirow{2}{*}{ Difference. } & \multirow{2}{*}{$\begin{array}{l}\text { Volume } \\
\text { distilled. }\end{array}$} \\
\hline Immersed. ${ }^{1}$ & Emergent. & & & Immersed.1 & Emergent. & & \\
\hline 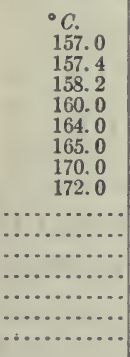 & \begin{aligned} &${ }^{\circ} C \\
& 153.5 \\
& 154.0 \\
& 155.0 \\
& 156.5 \\
& 160.0 \\
& 162.0 \\
& 166.0 \\
& 167.0 \\
&$. \hdashline$\ldots . .6 \\
&$\hdashline \\
& \hdashline\end{aligned} & $\begin{array}{r}{ }^{\circ} C . \\
3.5 \\
3.4 \\
3.2 \\
3.5 \\
4.0 \\
3.0 \\
4.0 \\
5.0\end{array}$ & $\begin{array}{r}c c . \\
7 \\
26 \\
108 \\
166 \\
173 \\
183 \\
184\end{array}$ & $\begin{array}{l}{ }^{\circ} C . \\
156.0 \\
158.0 \\
159.2 \\
160.2 \\
165.0 \\
167.0 \\
169.4 \\
170.0 \\
175.0 \\
177.0 \\
180.0 \\
185.0 \\
190.0 \\
195.0 \\
200.0\end{array}$ & $\begin{array}{l}{ }^{\circ} C . \\
151.0 \\
154.0 \\
155.0 \\
156.5 \\
162.0 \\
163.0 \\
165.0 \\
166.0 \\
170.0 \\
172.0 \\
174.0 \\
178.0 \\
183.0 \\
187.0 \\
192.0\end{array}$ & $\begin{array}{r}{ }^{\circ} C . \\
5.0 \\
4.0 \\
4.2 \\
3.7 \\
3.0 \\
4.0 \\
4.5 \\
4.0 \\
5.0 \\
5.0 \\
6.0 \\
7.0 \\
7.0 \\
8.0 \\
8.0\end{array}$ & $\begin{array}{c}c c . \\
\ldots . . . . \\
12 \\
28 \\
83 \\
99 \\
131 \\
136 \\
151 \\
155 \\
159 \\
163 \\
166 \\
168 \\
170\end{array}$ \\
\hline
\end{tabular}

1 Thermometer immersed in vapor only.

The table shows that No. 1 turpentine begins to distill at $157^{\circ} \mathrm{C}$. $\left(315^{\circ} \mathrm{F}\right.$.) by the immersed thermometer and at $153.5^{\circ} \mathrm{C}$. $\left(308^{\circ} \mathrm{F}\right.$.) by the emergent thermometer. At $160^{\circ}$ C. $\left(320^{\circ} \mathrm{F}\right.$.) by the immersed, $108 \mathrm{cc}$ had distilled, and by the emergent thermometer $166 \mathrm{cc}$. At $165^{\circ}$ C. $\left(329^{\circ}\right.$ F.) by the immersed thermometer 173 cc had distilled, while about $180 \mathrm{cc}$ had passed over when this temperature was reached by the emergent thermometer. It will be noted also that as the temperature rises, the difference between the readings of the two thermometers first decreases and then increases; the difference in reading being least where approximately the largest volume of distillate is yielded. These facts are brought out still more strikingly in the distillation of turpentine No. 2. The lag of the emergent stem thermometer is also shown in the comparison of the initial distilling temperature. The calculated correction for the emergent stem thermometer at $160^{\circ}$ is $2^{\circ}$, while the actual correction as determined by experiment was never less than $3^{\circ}$. These figures show how necessary it is, if comparative data as to the progress of a distillation are desired to have the stem of the thermometer entirely immersed in the vapor, and they also indicate that corrections made under ordinary laboratory conditions for emergent stem and lag are likely to be inadequate.

\section{EFFECT OF VARIATIONS IN ATMOSPHERIC PRESSURE.}

Variations in atmospheric pressure may affect the volume of the distillate at any given temperature even more than errors introduced by reading temperatures on emergent thermometers. The effect of variations in pressure on the distillation of two turpentines is shown in the table on page 16 . 
Variations in amounts of turpentine distilled caused by different barometric pressures.

[200 cc of turpentine distilled.]

\begin{tabular}{|c|c|c|c|c|c|c|c|}
\hline \multicolumn{4}{|c|}{ Turpentine No. 1.} & \multicolumn{4}{|c|}{ Turpentine No. 2.} \\
\hline \multirow{2}{*}{$\begin{array}{l}\text { Tempera- } \\
\text { ture. }\end{array}$} & \multicolumn{2}{|c|}{$\begin{array}{l}\text { Amounts distilled } \\
\text { at different baro- } \\
\text { metric pressures. }\end{array}$} & \multirow{2}{*}{$\begin{array}{l}\text { Differ- } \\
\text { ence. }\end{array}$} & \multirow{2}{*}{$\begin{array}{l}\text { Tempera- } \\
\text { ture. }\end{array}$} & \multicolumn{2}{|c|}{$\begin{array}{l}\text { Amounts distilled } \\
\text { at different baro- } \\
\text { metric pressures. }\end{array}$} & \multirow{2}{*}{$\begin{array}{l}\text { Differ- } \\
\text { ence. }\end{array}$} \\
\hline & $740 \mathrm{~mm}$. & $780 \mathrm{~mm}$. & & & $740 \mathrm{~mm}$. & $780 \mathrm{~mm}$. & \\
\hline $\begin{array}{c}{ }^{\circ} C . \\
157.4 \\
159.0 \\
160.0 \\
165.0 \\
170.0 \\
\ldots \ldots . .\end{array}$ & $\begin{array}{r}c c . \\
7 \\
53 \\
108 \\
173 \\
183\end{array}$ & $\begin{array}{c}c c . \\
\cdots 10 \\
163 \\
180 \\
\ldots \ldots\end{array}$ & $\begin{array}{r}c c . \\
\ldots . \\
98 \\
10 \\
3\end{array}$ & $\begin{array}{l}{ }^{\circ} C . \\
159.2 \\
160.0 \\
165.0 \\
170.0 \\
175.0 \\
180.0\end{array}$ & $\begin{array}{r}c c . \\
12 \\
26 \\
99 \\
136 \\
151 \\
159\end{array}$ & $\begin{array}{c}c c . \\
12 \\
60 \\
120 \\
143 \\
156\end{array}$ & $\begin{array}{r}c c . \\
14 \\
33 \\
13 \\
8 \\
6\end{array}$ \\
\hline
\end{tabular}

These results show that in the early stages of the distillation the quantities distilled at the two pressures differed widely; more widely on the turpentine distilling at the lower temperatures and within the narrower limits. As distillation approached completion these differences decreased, becoming negligible when 90 per cent of No. 1 had distilled, but remaining large when 80 per cent of No. 2 had passed over.

The distillation of normal fresh turpentine, of which more than 80 per cent passes over below $165^{\circ} \mathrm{C}$. $\left(329^{\circ} \mathrm{F}\right.$.), is greatly affected by variations in pressure; and it is quite clear that in obtaining the initial distilling temperature and other distillation data at temperatures below $165^{\circ} \mathrm{C}$., the pressure should always be the same. As distillation proceeds and the temperature rises the effect of variations in pressure on the total amount of turpentine distilled becomes less, so that ordinarily (that is, on a turpentine 90 per cent or more of which distills below $170^{\circ} \mathrm{C}$.) when the distilling temperature rises to $170^{\circ} \mathrm{C}$. the total quantity distilled at $740 \mathrm{~mm}$ or at $780 \mathrm{~mm}$ is almost the same, and for all practical purposes the difference may be disregarded. When the percentage distilling above $170^{\circ} \mathrm{C}$. is large, however, as in the case of No. 2, the difference due to the variation in pressure is large and not to be ignored. If it is desired, therefore, to determine the percentage distilled below $170^{\circ} \mathrm{C}$. to determine accurately the initial boiling point, or to trace the course of the distillation throughout its entire range, the barometric pressure should always be corrected to $760 \mathrm{~mm}$.

\section{DETECTION OF ADULTERANTS.}

The majority of the samples analyzed were examined only for mineral oils, as these are the principal adulterants employed. Methods for the detection of certain other adulterants were studied, however, and the results obtained will be discussed. Wood turpentine was not detected in any of the samples examined. 
SIGNIFICANCE OF ODOR, COLOR REACTIONS, AND BEAD.

Straight wood turpentines are readily distinguished from gum turpentines by their odor, or when they have been very carefully refined, by the odor of the first fraction, or of the residue from fractional distillation. One or both of these portions have the peculiar "sawmill smell," and the residue has a camphoric and somewhat nauseating odor characteristic of wood turpentine, which is quite different from the mild, sweet fragrance of gum turpentine.

Destructively distilled wood turpentine and also rosin spirits are more readily distinguished from gum spirits by their odor than is wood turpentine prepared by steam distillation, and they also give distinguishing color reactions when mixed with sulphurous acid as suggested by Hertzfeld or with hydrochloric acid (the presence of tin or zinc is not necessary) as suggested by Grimaldi. When steamdistilled wood turpentine has been carefully refined so that 90 to 95 per cent of it distills at from $155^{\circ}$ to $170^{\circ} \mathrm{C}$. $\left(311^{\circ}\right.$ to $338^{\circ} \mathrm{F}$.), both of these color tests are practically useless.

Turpentine adulterated with more than 10 to 20 per cent of coal-tar oils, or of gasoline or kerosene which have not been deodorized, may usually be readily detected by the characteristic odor of the mixture. The odor of rosin spirits, while quite distinctive, is difficult to detect in mixtures with turpentine. The presence of petroleum oils is also indicated by bubbles or "beads" persisting for a few moments on the surface of the turpentine shaken in a partly filled bottle.

The presence of more than about 10 per cent of kerosene or similar mineral oils is readily detected by the spot which a few drops of the sample placed on white paper leaves on drying. Gasoline and other light mineral oils do not leave this spot.

MINERAL OIL.

It is possible so to adulterate turpentine that neither the specific gravity, refractive index, or flash point is materially altered. Such careful adulteration is, of course, very rare, but as adulterants can not invariably be detected by making these determinations, and further, as mineral oil is the most probable adulterant, it is more rational to at once polymerize the suspected sample, note the volume, color, and consistency of the unpolymerized residue, and determine its refractive index.

The detection of mineral oils in turpentine is relatively quite simple, and is accomplished by mixing the turpentine with a certain proportion of sulphuric acid of a given strength, in which the turpentine is destroyed and mixes with the acid while most of the mineral oil remains unaffected and separates in a layer on top of the acid. The polymerization or sulphonation of turpentine, as this operation is 72457-Bull. $135-11-3$ 
called, as improved by Mr. Donk and conducted in the Bureau of Chemistry, is as follows:

Place approximately $2.5 \mathrm{cc}$ of exactly 38 times normal sulphuric acid in a flask holding approximately $50 \mathrm{cc}$ and having a graduated neck. The ordinary Babcock milk-test bottle serves admirably, and being a stock article is readily obtainable. Cool the flask in ice and run in without mixing $5 \mathrm{cc}$ of the turpentine to be tested. If the turpentine is pure and recently distilled, the charred surface will have a green fluorescence when held to the light and the underlying sulphuric acid will be clear and slightly colored. As little as 5 per cent of mineral oil prevents the green fluorescence and gives the sulphuric acid a muddy appearance. Gum and wood turpentine containing considerable quantities of heavy terpenes also lack fluorescence and are muddy in appearance. Mix the turpentine with the acid by cautious shaking, keeping the temperature below $65^{\circ} \mathrm{C}$. $\left(149^{\circ} \mathrm{F}\right.$.) by frequent immersion in ice. When the temperature no longer increases on shaking (determine by the touch), shake vigorously to insure perfect contact between the acid and the turpentine, place the flask in water at about $40^{\circ} \mathrm{C}$. $\left(104^{\circ} \mathrm{F}\right.$.), and heat slowly to $65^{\circ}$, shaking vigorously and frequently. When this temperature is attained, give a final vigorous shaking; cool, bring the unpolymerized layer into the neck by running in ordinary sulphuric acid, centrifuge or let stand for two hours, read the volume of unpolymerized.clear top layer and immediately determine its refractive index, withdrawing a portion from the top of the clear layer only for this purpose. The character and quantity of this layer or residue will show whether or not the turpentine is adulterated with mineral oil. If the turpentine is pure, the residue will seldom exceed 1 per cent; it will be very viscous, and will have a refractive index at $20^{\circ} \mathrm{C}$. of 1.5000 to 1.5200 . If the sample contains mineral oil, however, the residue will be limpid or oily and colorless and will have a refractive index at $20^{\circ} \mathrm{C}$. between 1.4200 and 1.4950 .

It is characteristic of mineral oils that the refractive index of the unpolymerized oil is lower than that of the original sample, while that of the residue from turpentine is higher. The results are not quantitative, as when 5 per cent of mineral oil is present approximately 80 per cent of it is taken up by the sulphuric acid, when 10 per cent of mineral oil is present approximately 60 per cent, and when 20 per cent is present approximately 50 per cent of mineral oil is destroyed in polymerization. When a straight mineral oil is treated with the 38 normal sulphuric acid, about 25 per cent of it is acted upon. For kerosene these figures are much lower. In this report residues greater than 1 per cent are considered to be mineral oil and no correction is made for the amount destroyed in polymerization. These results are therefore low, giving the benefit of the known action of the acid on the mineral oil entirely to the seller.

In a number of instances when the volume of the residue after polymerization did not indicate the presence of mineral oil but its refractive index or limpidity did, the turpentine was distilled, and the portion which did not distill below $170^{\circ} \mathrm{C}$., and several of the fractions from the distillation were subjected to the sulphuric-acid test. As a rule, the portion which did not distill below $170^{\circ} \mathrm{C}$. left more residue after polymerization than the original turpentine did and it possessed more decidedly the characteristics of mineral oil, i. e., low 
refractive index and limpidity. The undistilled portion of pure turpentine when treated in the same way either foamed out of the flask or was instantly reduced to a charred mass and left no measurable residue.

ROSIN SPIRITS.

If rosin spirits is present in notable quantities, it may be detected by the amount of residue on polymerization in conjunction with lowered initial boiling point and the deep coloration produced by mixing portions of the original turpentine or the first fraction with sulphurous acid and with hydrochloric acid.

If the initial distilling temperature of the turpentine is less than $154^{\circ} \mathrm{C}$. and the original sample gives a reddish color with sulphurous acid and a greenish red with hydrochloric acid, and the residue from polymerization is less than 5 per cent, ${ }^{1}$ it is probable that the sample is adulterated with rosin spirits. An odor of rosin spirits in the sample, or in any fraction, would be confirmatory, and all tests should be repeated on the first fraction, obtained with a fractionating column. At best the detection of small amounts of rosin spirits is very difficult, and the procedure outlined may often fail to detect its presence.

COAL-TAR OILS.

The presence of marked quantities of coal-tar oils, benzol, toluol, and xylol is detected by the odor, the lower initial distilling temperature, i. e., between $80^{\circ}$ and $155^{\circ}$ C. $\left(176^{\circ}\right.$ and $311^{\circ} \mathrm{F}$.), and by further examination of the first fractions which distill below $155^{\circ} \mathrm{C}$. $\left(311^{\circ} \mathrm{F}\right.$.). The rise of temperature on shaking during polymerization is also indicative of the nature of the sample. Coal-tar and petroleum oils do not raise the temperature more than $35^{\circ}$ or $40^{\circ} \mathrm{C}$. $\left(95^{\circ}\right.$ or $104^{\circ} \mathrm{F}$.), when mixed with sulphuric acid. When the temperature of turpentine mixed with 38 normal sulphuric acid does not rise above $50^{\circ}$ or $60^{\circ} \mathrm{C}$. $\left(122^{\circ}\right.$ or $140^{\circ} \mathrm{F}$.), it is evident that mineral oil, coal-tar oil, or some other oil than turpentine is present in large quantities. The older the sample of turpentine, the greater, or at least the more rapid, the rise of the temperature of the mixture. When the initial distilling temperature of the sample is less than $154^{\circ}$ C. $\left(309^{\circ}\right.$ F.) and there is less than 1 per cent of residue on polymerization, the presence of coal-tar oils is to be suspected. The sample should be carefully fractionated with a column, the initial distilling temperature noted, and that portion distilling below $157^{\circ} \mathrm{C}$. $\left(315^{\circ} \mathrm{F}\right.$.) carefully examined. A refractive index at $20^{\circ} \mathrm{C}$. greater than 1.475 is strongly indicative of coal-tar oils and the test should be repeated, distilling a sufficient quantity of the sample to obtain at least 50 ce fractionating below $157^{\circ} \mathrm{C}$. $\left(314^{\circ} \mathrm{F}\right.$.), which should be 
carefully refractionated, the initial distilling temperature noted, and the refractive index, behavior with sulphuric acid (color, heat developed, refractive index of residue, if any), and odor closely observed. An initial distilling temperature of less than $154^{\circ} \mathrm{C}$. $\left(309^{\circ} \mathrm{F}\right.$.) with a refractive index of the first fraction of more than 1.475 , together with a reddish color and but little development of heat on mixing with the sulphuric acid, and the characteristic odor of the oils, is proof of the presence of coal-tar oils.

When the proportion of coal-tar oils is small, this examination may not always give positive evidence of their presence. As little as 5 per cent of xylol, however, may be identified by the following procedure:

To 150 cc of 4 to 1 sulphuric acid, in a separatory funnel, add $100 \mathrm{cc}$ of the suspected turpentine, being careful to prevent a rise in temperature above $40^{\circ} \mathrm{C},\left(104^{\circ} \mathrm{F}\right.$.). Mix thoroughly, keeping the temperature below $40^{\circ} \mathrm{C}$., draw off the polymerized portion, transfer the unpolymerized portion to a small distilling flask, and distill slowly, changing the receiver when the distillate ceases to be clear, colorless, and limpid. The temperature at this time should not exceed $180^{\circ}$ C. $\left(356^{\circ}\right.$ F.). A turpentine containing 5 per cent of xylol, when treated in this way, gave about $3 \mathrm{cc}$ distilling below $180^{\circ} \mathrm{C}$. $\left(356^{\circ} \mathrm{F}\right.$.). The refractive index was 1.475 , the odor that of xylol, and on adding nitric acid a strong odor of nitro-xylol was obtained. This treatment of turpentine with dilute sulphuric acid converts it into a heavy oil (with a refractive index of $1.5+$ ), and not more than a few cubic centimeters will distill from, the mixture below $300^{\circ} \mathrm{C}$. $\left(572^{\circ} \mathrm{F}\right.$.). The method has not so far been sufficiently developed to be of quantitative value, so that the proportion of coaltar oils present can only be approximated within wide limits.

Nonvolatile oils are, of course, readily detected by distillation, and their nature, so far as it may be determined, is learned by the usual methods.

\section{DISCUSSION OF DATA ON UNADULTERATED SAMPLES.}

It will be observed in studying the detailed analytical data that a few samples, which undoubtedly do not contain added adulterants, show some inconsistencies among the figures for specific gravity, refractive index, and behavior on distillation. While, as has been mentioned, this fact is partially accounted for by the use of emergent. stem thermometers and the variation in barometric pressure, it is certainly not always due entirely to these causes, but also partly to the fact that, in examining so large a number of samples, it was impracticable to make all the determinations on each sample at one time, and changes occurred in these few turpentines in the time that elapsed between the beginning and the ending of their analysis. For some of 
the samples two sets of results are given. They show that while some have undergone no alteration even after 18 months others have continued to change. All of the figures on the latter samples are of interest as indicative of the changes which may take place in turpentines during aging. The results on the turpentines which had evidently changed greatiy were not considered in forming a judgment regarding the individual constants of turpentine.

The following summary of the analytical data on unadulterated turpentines, based on the detailed figures given in Tables I and II, shows the extremes obtained:

Summary of analytical data on unadulterated turpentines.

\begin{tabular}{|c|c|c|}
\hline Determinations. & Minimum. & Maximum. \\
\hline 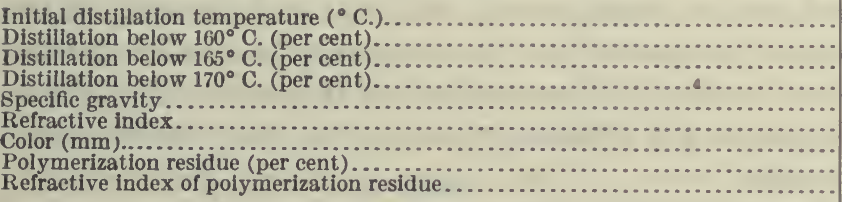 & $\begin{array}{l}154.5 \\
42.0 \\
68.8 \\
77.3 \\
.8617 \\
1.4684 \\
2.0 \\
1.2 \\
1.500\end{array}$ & $\begin{array}{l}159.0 \\
94.0 \\
98.6 \\
99.1 \\
.8989 \\
1.4818 \\
800.0 \\
1.0 \\
1.5150\end{array}$ \\
\hline
\end{tabular}

In setting these limits the results on several samples have been ignored, because there was doubt as to the purity of the sample, or as to the exactness of the results.

The summarized data show that turpentines which are unadulterated, in the sense that they have had nothing added to or taken from them, give widely different results when analyzed under the usual conditions. Thus unadulterated turpentine may begin to distill, under the conditions obtaining in this work, at from $154.5^{\circ}$ to $159^{\circ} \mathrm{C}$. The amount distilled below $160^{\circ} \mathrm{C}$. varies from 42 to 94 per cent, below $165^{\circ}$ from 69 to 99 per cent, and below $170^{\circ}$ from 77 to 99 per cent. The specific gravity ranges from 0.8617 to 0.8989 at $20^{\circ} \mathrm{C}$. and the refractive index from 1.4684 to 1.4818 . The residue on polymerization with 38 normal sulphuric acid ranges from 0.2 to 1.0 per cent, and the refractive index of this residue at $20^{\circ} \mathrm{C}$. may be as high as 1.5200 but should never be below 1.500. These differences are due to natural variations in the freshly distilled turpentine, to aging, and to variations in conditions of analysis.

It should be borne in mind that many samples of old turpentine are undoubtedly represented in this lot, as well as turpentines stored in wood and in metal, and in clean containers as well as in tanks which still held the residues of previous purchases. In other words, the samples fairly represent those found on the wholesale and retail market at any time. Certain of these samples can not be properly termed turpentine because they do not possess the constants of turpentine. 
It has been pointed out that in aging, turpentine undergoes change; it becomes heavier, thicker, and deeper colored and the odor is different. With age specific gravity and refractive index may become higher, the quantity distilling below $170^{\circ} \mathrm{C}$. less, the color deeper, and polymerization with sulphuric acid more rapid, and fully as complete. The increase in specific gravity or refractive index which occurs with age is well shown by the results on samples Nos. 6121, $6127,6135,6137$, and 6238 , on which two sets of results, the higher one obtained from 12 to 18 months later than the lower, are given. These samples had visibly changed in consistency and color; and the odor had also changed in the time elapsing between the two sets of determinations. Samples which showed no visible darkening or thickening had practically the same specific gravity and refractive index after 18 months as at first. As has been shown, partly because of this tendency to change with age and also because of the natural variations in the product, it is customary to specify certain limits within which the results of an analysis of turpentine should fall. The fixing of these limits for different grades is discussed under specifications for turpentine.

\section{EXTENT OF ADULTERATION WITH MINERAL OIL.}

The data showing the extent and distribution of the adulteration of turpentines, which is practically confined to the addition of mineral oils, may be summarized as follows, the detailed figures being given in Tables I and II, beginning on page 32 . Only those samples showing 1 per cent or more of mineral oil are counted as adulterated in this summary:

\section{Number and distribution of adulterated.samples.}

\begin{tabular}{|c|c|c|c|c|}
\hline Source of samples. & Number. & $\begin{array}{l}\text { Number } \\
\text { adulter- } \\
\text { ated. }\end{array}$ & $\begin{array}{l}\text { Per eent } \\
\text { adulter- } \\
\text { ated. }\end{array}$ & $\begin{array}{l}\text { Per cent of } \\
\text { adulterant } \\
\text { present. }\end{array}$ \\
\hline 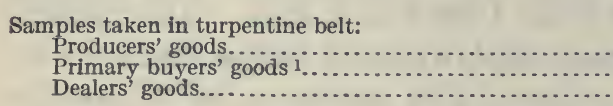 & $\begin{array}{l}71 \\
44 \\
99\end{array}$ & $\begin{array}{r}3 \\
6 \\
18\end{array}$ & $\begin{array}{r}4.2 \\
13.6 \\
18.0\end{array}$ & $\begin{array}{l}2.9 \\
2.2 \\
6.4\end{array}$ \\
\hline Totals and averages... & 214 & 27 & 12.6 & 5.0 \\
\hline 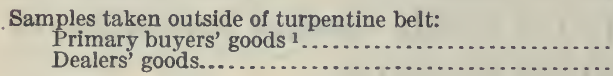 & $\begin{array}{r}7 \\
205\end{array}$ & $\begin{array}{r}0 \\
50^{\circ}\end{array}$ & 24.4 & 10.6 \\
\hline Totals and averages.. & 212 & 50 & 24.0 & 10.6 \\
\hline General totals and averages. & 426 & 77 & 18.0 & 6.1 \\
\hline
\end{tabular}

1 Buyers purchasing through factors.

The figures indicate that only a few of the samples of producers' goods are adulterated with mineral oils, while the turpentine of the primary buyers and dealers in the turpentine belt is adulterated extensively, showing 13.6 and 18 per cent of adulterated samples, 
respectively. The dealers' samples contain a much higher percentage of the adulterant than either of the other two classes, exceeding the producers' goods by 3.5 and the primary buyers' goods by 4.2 per cent. It will be observed also that adulterations occur more frequently and are present in larger quantities outside the turpentineproducing belt than within it. Eighteen per cent of all the samples collected were adulterated, and the average percentage of adulterant in these was 6.1 per cent, ranging from 1 to 71 per cent in the individual samples. The average amount of mineral oil in a barrel of the adulterated samples was approximately 3 gallons, which, basing the calculation simply on the cost of the two materials, made these adulterated turpentines worth fully $\$ 1.50$ less per barrel than unadulterated stock. These facts assume graver significance when it is remembered that turpentine is an article so well known and so generally used that it is carried in stock and sold by merchants generally, particularly by country merchants, and when bought from any source is liable to be employed indiscriminately, either medicinally or technically.

These samples having been carefully taken from all sections of the country, this statement regarding the percentage of adulterated turpentine may be considered as fairly representative of the general conditions in the turpentine trade. The consumption of turpentine in the United States during 1908 was approximately 15,000,000 gallons. If 18 per cent of this was adulterated, then approximately $3,000,000$ gallons of adulterated turpentine, containing an average of at least 6 gallons per hundred of mineral oil, costing about one-fifth as much as the turpentine, was sold at turpentine prices. The small percentage of mineral oil found in some samples may have been occasioned by mixing a barrel of heavily adulterated turpentine with a large quantity of a pure product, or possibly by putting turpentine into improperly prepared petroleum barrels or into tank cars previously used for mineral oils.

\section{EXAMINATION OF STANDARD GRADE SAMPLES.}

The proper grading of turpentine is a matter of no small monetary importance to the producer and primary buyer, and the boards of trade of the turpentine markets have adopted rules and standards for the purpose of correct and consistent grading. These standards are selected by the naval stores inspectors and passed upon by the naval stores committee of the boards of trade. The generally accepted final authority is the New York naval stores committee, whose inspector, as a matter of fact, selects practically all standard samples of turpentine and rosin used by naval stores inspectors of this country.

For the purpose of learning how closely the standard samples on which turpentine is bought in the primary markets agree among themselves, sets of standards were secured from the Savannah, Ga., and 
Jacksonville, Fla., boards of trade and also from the inspectors of the New York naval stores committee.

The color of these samples was read against the standard yellow glass on the Lovibond tintometer, marked " 1 ." The turpentine was placed in a graduated $200-\mathrm{mm}$ tube and the depth of the column of turpentine required to equal the color of the glass was carefully noted, using the Schreiner type of colorimeter. The longer the column of turpentine required to match the glass, the less color there is in the turpentine. The results are expressed in millimeters, which show the length of column or depth of turpentine required to equal the standard yellow glass No. 1. The following results were obtained on these standard samples:

Comparison of standard turpentine samples from different sources.

Sample marked -
$\ldots$

1 This sample probably should have been marked "water white."

These results show that the standard samples obtained from different sources are far from uniform and indicate different practices on the chief primary markets. It is the usual custom, however, as previously stated, to mix small quantities of off-shade turpentine with the standard or water-white products and thus the off-shade output is used and sold without getting beyond the primary markets. The variations noted in the standards have, therefore, but little significance in the retail trade where, in general, but one grade of turpentine is recognized, though, as will be seen by consulting the tables, there is a great variation in the color of commercial turpentine, which point as an indication of quality should undoubtedly receive more careful consideration from the consumer than it does.

\section{PROPOSED SPECIFICATIONS FOR TURPENTINE.}

Buyers of large quantities of turpentine have long specified certain tests with which the turpentine they purchased must comply. In the main, most of these are reasonable and will be met by carefully made turpentine when freshly distilled. The constants and standards thus set differ slightly in different specifications, and some of them are unnecessarily severe, causing the rejection of much good turpentine. It seems well, therefore, to suggest specifications for 
turpentine, which, while fully protecting the consumer, recognize the natural variations occurring even in the freshly distilled turpentine.

This investigation, however, shows clearly that by no means all of the unadulterated turpentine sold can be regarded of the same quality, nor does it comply with the accepted standards. This fact is fully accounted for by natural differences in the crude turpentine, negligence on the part of the turpentine producer, irregularities in distilling, and differences in age and methods of storing. A turpentine with a specific gravity of 0.875 , only 50 per cent of which distills below $160^{\circ} \mathrm{C}$. and $20 \mathrm{~mm}$ of which equals in color the No. 1 Lovibond glass, is certainly not of the same grade as one having a specific gravity of $0.865,90$ per cent distilling below $160^{\circ} \mathrm{C}$. and $150 \mathrm{~mm}$ of which is needed to equal the No. 1 glass in color. Nevertheless the former is turpentine, though its value is somewhat less than the latter. It appears but just and reasonable that several well-defined grades of turpentine should be recognized and standard specifications established for them. Such standards are accordingly suggested for the consideration and criticism of producers and consumers of turpentine.

Standard or No. 1 turpentine should have a specific gravity at $20^{\circ}$ C. of from 0.862 to 0.870 ; a refractive index at $20^{\circ} \mathrm{C}$. of from 1.468 to 1.476 ; 95 per cent should distill below $170^{\circ} \mathrm{C}$., and a layer of not less than $200 \mathrm{~mm}$ should be required to equal in color the Lovibond yellow glass No. 1. On polymerization with 38 normal sulphuric acid the residue should not exceed 1 per cent, should be reddish in color and viscous, and its refractive index at $20^{\circ} \mathrm{C}$. should be from 1.500 to 1.520 . An unadulterated turpentine which does not agree with these requirements may properly be regarded as not of standard or No. 1 quality.

Second quality or No. 2 turpentine should have a specific gravity at $20^{\circ} \mathrm{C}$. of from 0.862 to 0.875 ; a refractive index at $20^{\circ} \mathrm{C}$. of from 1.468 to $1.480 ; 90$ per cent should distill below $170^{\circ} \mathrm{C}$. and a depth of not less than $100 \mathrm{~mm}$ should be required to equal the Lovibond yellow glass No. 1. The polymerization residue must not exceed 1 per cent and must have a refractive index of not less than 1.50.

Third quality or No. 3 turpentine should have a specific gravity at $20^{\circ} \mathrm{C}$. of from 0.865 to 0.880 ; a refractive index at $20^{\circ} \mathrm{C}$. of from 1.468 to $1.485 ; 60$ per cent should distill below $170^{\circ} \mathrm{C}$. and a depth of not less than $50 \mathrm{~mm}$ should be required to equal the Lovibond yellow glass No. 1. The polymerization residue must not exceed 1 per cent and must have a refractive index of not less than 1.500.

These specifications are applicable to both gum spirits turpentine and to "wood turpentine," and are in general harmony with trade practice. For high-grade varnishes and for medicinal purposes a colorless, light turpentine which evaporates rapidly and will hasten drying, leaving the varnish firm and not "tacky," is desirsd. For 
lower-grade varnishes and good quality paints a somewhat colored and slower evaporating product may be successfully employed. In the case of low-grade paints, especially those where the drying is hastened by vigorous means, or in all cases when slow drying is desired, the heavier, slower evaporating turpentine, or even what is known as "pine oil," may prove most suitable.

\section{METHODS FOR THE EXAMINATION OF TURPENTINE FOR PURITY AND QUALITY.}

The work done in connection with this investigation has developed a number of improvements in the methods for examining turpentine which increase the accuracy of the results and insure greater concordance in the work of different chemists. The methods to be given have been in use in this laboratory for from one to three years and have been found satisfactory.

All tests of a turpentine should be promptly made, usually within the same week, because some samples change rapidly in consistency, color, gravity, behavior on distillation, and refractive index, and if the several determinations are made at long intervals those last made may not represent the turpentine as first received. Further, all of the results on a sample may not be strictly comparable and may lead to errors in judging the turpentine.

\section{COLOR.}

Determine color in a graduated $200 \mathrm{~mm}$ tube in a colorimeter reading against the Lovibond yellow glass No. 1 . If a depth of $200 \mathrm{~mm}$ or more is required to match the glass the color is No. 1; if a depth of from 100 to $200 \mathrm{~mm}$ is required the color is No. 2; if a depth of from 50 to $100 \mathrm{~mm}$ is required it is No. 3; and if less than $50 \mathrm{~mm}$ the color is No. 4 .

\section{SPECIFIC GRAVITY.}

Determine specific gravity with a pyknometer, plummet, Westphal balance, or accurate hydrometer. The determination may be made at $15.5^{\circ}$ or at $20^{\circ} \mathrm{C}$, as desired.

\section{DISTILLATION.}

\section{APPARATUS.}

Heating bath.-Use a copper cup of about 800 cc capacity, having a concave tight-fitting cover (which may be fixed) with a hole in it large enough to hold a $300 \mathrm{cc}$ distilling flask, and also a one-half inch condensing tube 12 inches long, rising from one side of the cup. This serves as a condenser for the vapors of glycerin or oil used in the bath, and prevents the superheating effect of vapors which would otherwise be in contact with the exposed portion of the distilling flask. 
Distilling flask.-Comparable results can only be obtained in distillation by always using flasks of the same dimensions. The flask found most satisfactory in this work is an ordinary 300 cc flask, $8 \mathrm{~cm}$ in diameter, with the side tube $8 \mathrm{~cm}$ from the main bulb, and the neck extending $8 \mathrm{~cm}$ above the side tube. The neck is $2 \mathrm{~cm}$ in diameter and the side tube is $5 \mathrm{~mm}$.

Manometer.-An open manometer with a movable scale graduated in millimeters, and provided with double connections, must also be provided.

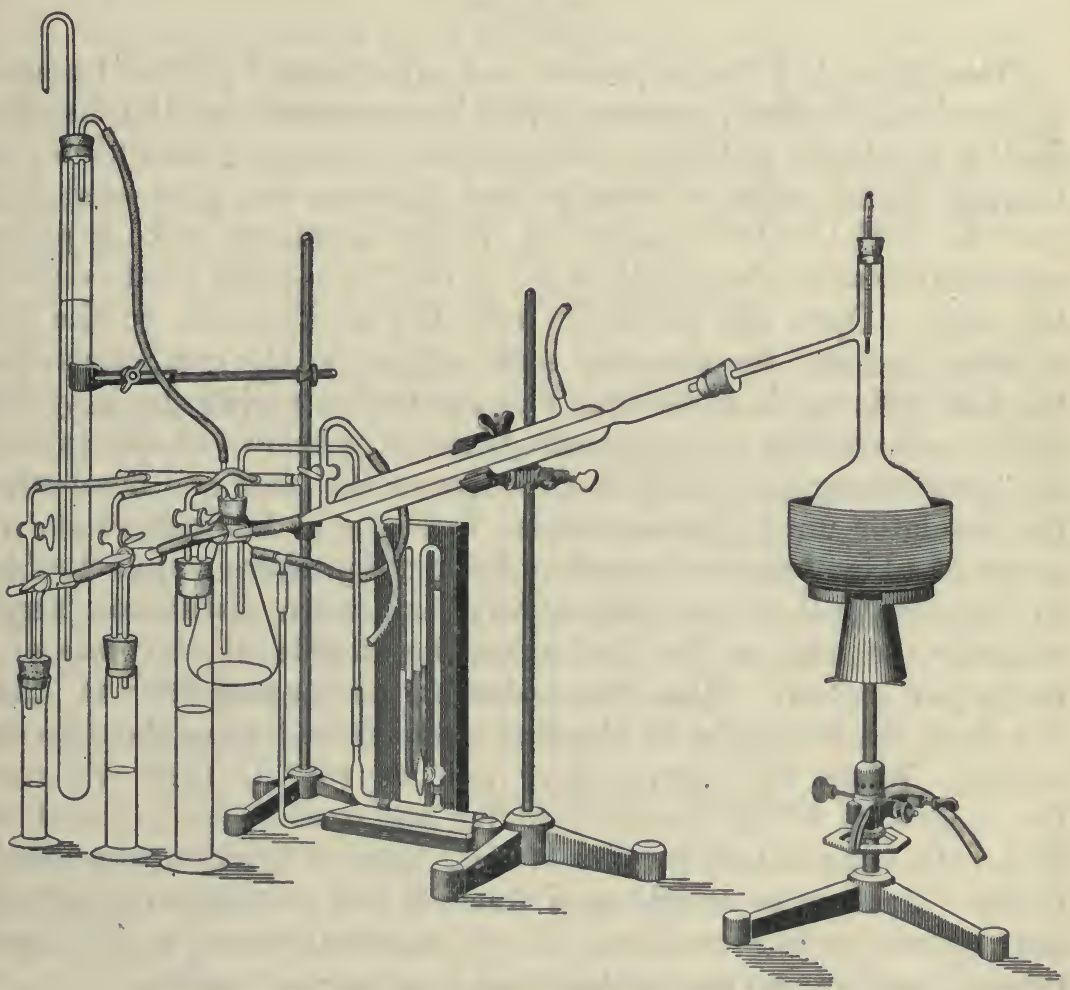

FIG. 1.-Apparatus for the fractional distillation of turpentine.

Pressure regulator.-This consists of a glass tube about 1 inch in diameter and about 24 inches long, fused at one.end, nearly filled with water, and stoppered with a two-hole stopper, carrying two glass tubes, one of which extends to the bottom of the large tube, the other being free to move up or down.

Condenser and receivers.-An ordinary condenser is connected with three stoppered, graduated cylinders, by means of two-way stopcocks, care being taken to insure close connection and the exposure of a minimum length of tubing to the turpentine. The stopper of each cylinder is provided with a stopcock connection with an air chamber, 
which is in turn connected with the pressure regulator and with the manometer. By connecting a blast or vacuum with the air chamber, which in turn is connected with the free end of the proper tube of the pressure regulator any desired pressure (within the limits of the apparatus) can be produced in the system. The apparatus is shown in figure 1. All corks and connections must be absolutely air tight. If they are not, the fact will be indicated by the sudden fluctuation of the thermometer when the cock between a receiving cylinder and the pressure flask is opened.

\section{OPERATION.}

Place $200 \mathrm{cc}^{1}$ of the turpentine and several small pieces of pumice in the distilling flask, connect with the condenser, set the distilling flask in the bath, and heat. Stopper the distilling flask with a cork through which passes a standardized thermometer graduated from $150^{\circ}$ to $200^{\circ} \mathrm{C}$. $\left(302^{\circ}\right.$ to $392^{\circ} \mathrm{F}$.). The mercury bulb is placed opposite the side tube and the $175^{\circ} \mathrm{C}$. $\left(347^{\circ} \mathrm{F}\right.$.) mark must be below the cork. Open the stopcock from the air chamber to the first cylinder and also the two-way cock connecting the condensers with the first cylinder, in order that the condensed turpentine may flow into it. According as the pressure is above or below $760 \mathrm{~mm}$ connect the pressure regulator with the vacuum or the blast and manipulate the regulator until the manometer indicates in millimeters the reduced or added pressure needed to bring the pressure within the flask to $760 \mathrm{~mm} .^{2}$ Heat the bath slowly, and when distillation begins regulate the heat so that the turpentine distills at the rate of 2 drops per second. When the thermometer reaches $160^{\circ} \mathrm{C} .\left(320^{\circ}\right.$ F.) close the stopcocks to the first cylinder and open those to the second. When the thermometer reaches $165^{\circ} \mathrm{C}$. $\left(329^{\circ} \mathrm{F}\right.$.) close the stopcocks to the second cylinder and open those to the third. When the temperature reaches $170^{\circ} \mathrm{C}$. $\left(338^{\circ} \mathrm{F}\right.$.) discontinue distillation. Measure or weigh each fraction and determine its specific gravity and refractive index. A polymerization test is also made on each fraction and the residue when it appears advisable.

When the residue not volatile at $170^{\circ} \mathrm{C}$. is large, and it is desired to continue distillation for any purpose, a clean cylinder may be put in the place of the first or second one and distillation continued as long as is deemed necessary. Of course as many fractions may be made as are desired, one with each change of $1^{\circ} \mathrm{C}$. in the distillation temperature, or with the distillation of definite volumes. Such a procedure, however, adds but little, if any, information of technical value. 
REFRACTIVE INDEX.

Determine the refractive index with a Zeiss direct reading refractometer at $20^{\circ} \mathrm{C}$.

\section{DETECTION OF ROSIN SPIRITS. ${ }^{1}$}

Note the initial distilling temperature and to one portion of the first fraction distilling below $160^{\circ} \mathrm{C}$. $\left(320^{\circ} \mathrm{F}\right.$.) add sulphurous acid and to another hydrochloric acid. An initial distilling temperature below $154^{\circ} \mathrm{C}$. $\left(309^{\circ} \mathrm{F}\right.$.), together with the development of a decided red color with sulphurous acid and a green color with hydrochloric acid, when accompanied by a polymerization residue of less than 5 per cent on the original sample, is indicative of rosin spirits. Refractionate 50 to $100 \mathrm{cc}$ of the first fraction, distilling below $160^{\circ} \mathrm{C}$. $\left(320^{\circ} \mathrm{F}\right.$.) with a column, note the initial distilling temperature, and repeat the color and polymerization tests. If they are more positive than before, rosin spirits is probably present.

\section{DETECTION OF COAL-TAR OILS. ${ }^{1}$}

To $150 \mathrm{cc}$ of sulphuric acid (4:1) in a separatory funnel, add $100 \mathrm{cc}$ of the suspected turpentine, being careful to prevent a rise in temperature above $40^{\circ} \mathrm{C}$. Mix thoroughly, keeping the temperature below $40^{\circ} \mathrm{C}$. $\left(104^{\circ} \mathrm{F}\right.$.), draw off the polymerized portion, transfer the unpolymerized portion to a small distilling flask, and distill slowly, stopping the distillation when the temperature reaches $180^{\circ} \mathrm{C}$. $\left(346^{\circ} \mathrm{F}\right.$.), or before if the distillate becomes cloudy, colored, or oily. Determine the refractive index, which should be 1.475 or more, and add cautiously a little nitric acid. The odor of nitrobenzol or nitro-xylol proves the presence of coal-tar oils.

\section{DETECTION AND ESTIMATION OF MINERAL OIL.}

The method used for the detection and estimation of mineral oil is an improvement of the Hertzfeldt method of polymerization with sulphuric acid and is based on the fact, observed by Mr. Donk, that the residue from turpentine is practically constant and negligible if the acid used is of a certain exact concentration. The method has been in use in this laboratory for about three years with perfectly satisfactory results.

Preparation of acid.-The sulphuric acid used is 38 times normal. This solution contains 100.92 per cent of sulphuric acid by weight and is prepared by adding fuming acid to the concentrated until a strongly fuming mixture is obtained. The exact strength is then determined by diluting and titrating a weighed portion (6 to 8 grams), using methyl orange as indicator. An accurate determination of the acid strength is absolutely necessary, as an acid contain- 
ing 100.82 per cent or 37.9 normal gives a residue decidedly greater than one containing 100.92 per cent of sulphuric acid, when the mineral oil present is 5 per cent or less. The acid is standardized as follows:

The acid is conveniently weighed in a bulb having a capillary tube at the lower end and a rather large tube with a glass stopcock in the upper end, fitted with a platinum wire for weighing. The pipette is filled by aid of a slight vacuum, and by closing the stopcock simultaneously with the withdrawal of the capillary from the acid the lower end of the capillary is emptied and may be cleaned on the exterior by wiping first with a wet and then with a dry piece of cloth. The pipette thus filled and dried may be left for hours without losing or gaining weight.

After weighing, dip the capillary into about $500 \mathrm{cc}$ of water in a large beaker, open the stopcock, and when the acid has run out, wash the pipette with water run in from the top through a rubber tube and funnel. Add a slight excess of sodium carbonate solution of known strength by weight ( 0.2 gram per gram of solution is convenient); this may be run in from a suitably arranged dropping or delivery flask (weighed before and after the operation) until the solution is slightly alkaline to methyl orange. Boil off the carbon dioxid, allow to cool, add methyl orange, and titrate back the excess carbonate with half normal sulphuric acid. Determine the specific gravity of the acid with a pyknometer, calculate its normality, and run in from a burette, having a long capillary delivery tube, enough water to dilute it to 38 normal.

Other procedures may suggest themselves and be preferred by different operators, but of the many methods of standardization tried, this one was found to be by far the most accurate and as expeditious as any, ordinary care holding the error below one-tenth of 1 per cent. It is needless to say that the acid must be carefully guarded against absorbing moisture from the air. Several liters of the acid should be prepared at a time and it should be stored in quarter or half liter bottles closed with tight-fitting glass stoppers.

Operation.-Transfer $20 \mathrm{cc}$ of this acid to a Babcock bottle (one having a $20 \mathrm{cc}$ mark is convenient), stopper, and place in ice water. After cooling, add 5 cc of the turpentine, again cool, and gradually mix the contents, cooling from time to time (the temperature should not be allowed to rise materially), and when the mixture no longer warms up after shaking, agitate thoroughly. Then place the bottle in a water bath in which the water is on a level with the acid and heat to from $60^{\circ}$ to $65^{\circ} \mathrm{C}$. $\left(140^{\circ}\right.$ to $149^{\circ} \mathrm{F}$.) in the course of about five minutes, keeping the contents thoroughly mixed by vigorously shaking six or seven times. Do not stopper the bottles after turpentine has been added. 
(As the destruction of the turpentine deperds upon its contact with the sulphuric acid, which in turn is dependent upon the minuteness of the turpentine particles suspended in the acid, it follows; and this is convincingly borne out by experience, that thorough mixing is one of the salient features of the method.)

Cool to room temperature, add ordinary sulphuric acid until the contents rise in the graduated portion of neck, and whirl at 1,200 revolutions per minute for three or four minutes, or allow to stand over night; read the amount of supernatant residue.

Discussion.-With a pure turpentine the residue will be straw colored, viscous, and if read at once will give a refractive index at $20^{\circ}$ C. of 1.5050 or higher and amount to from 0.02 to 0.05 cc. When adulterated with mineral oil the residue is a limpid, colorless liquid, having a refractive index of 1.4900 to 1.4300 or lower, depending on the kind and amount of adulterant present. When a small amount of adulterant has been added it is preferable to use a centrifugal machine reading the refractive index immediately, using the upper portion of the residue, as the mineral oil and residual turpentine are thus stratified, the low-reading mineral oil constituting the upper portion. A capillary pipette is used in transferring a small portion of the residual oil to the refractometer.

The results are always low, as members of the unsaturated aliphatic series are partly soluble in the acid used. When a mineral oil of an asphaltum base has been used as an adulterant, results are usually approximately too low by from 80 to 50 per cent. That is the percentage of mineral oil present that is polymerized by acid of the strength employed or that remains mixed with the acid is higher with low percentages of mineral oil and lower with high percentages. The method has been in use in this laboratory for several years in connection with pure food and drug work as well as in testing turpentine, paint, varnish, oils, etc., bought under Government contracts, and an experienced operator following the method strictly has no difficulty in detecting 2 per cent of adulterant. 


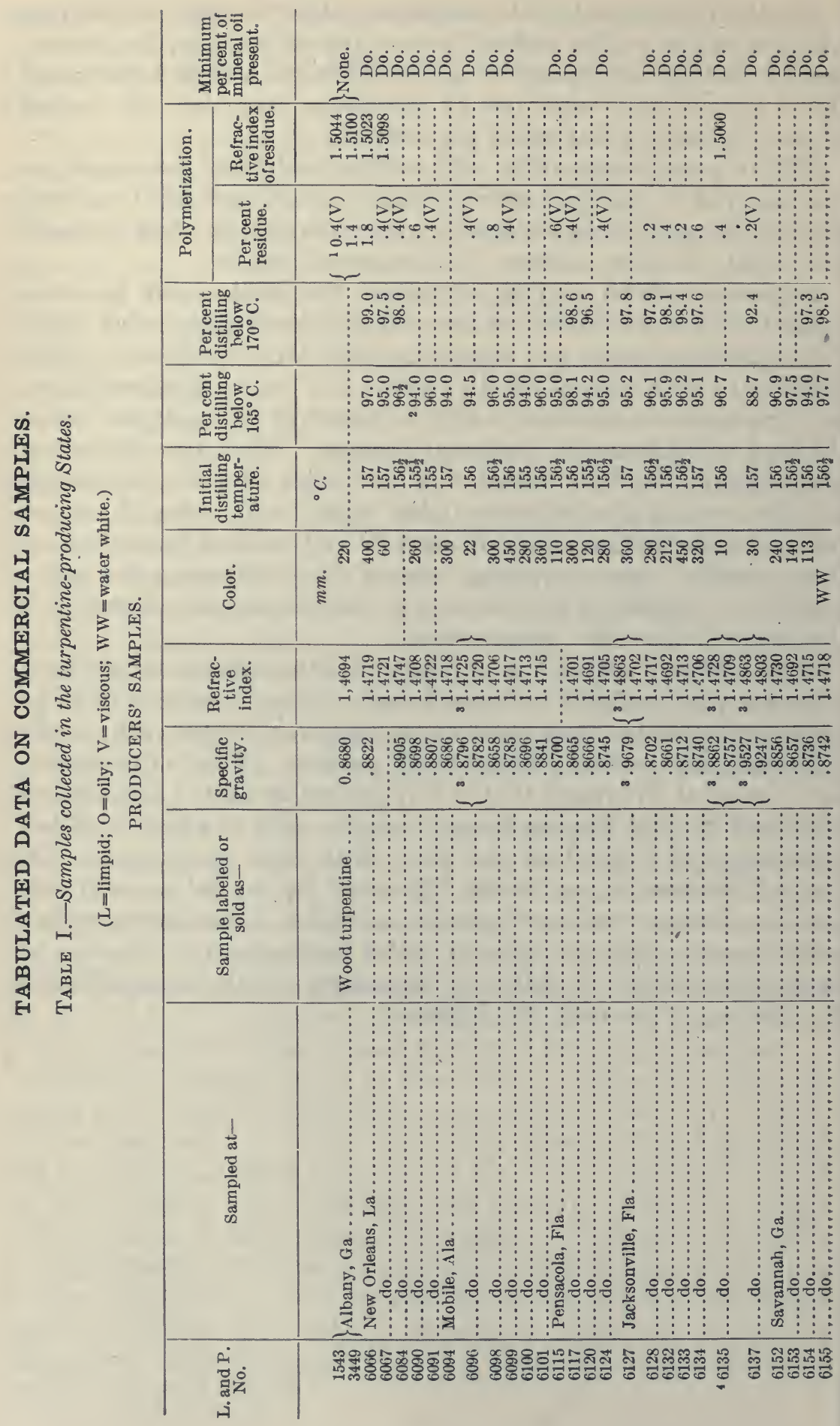




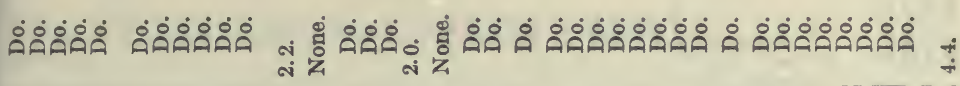

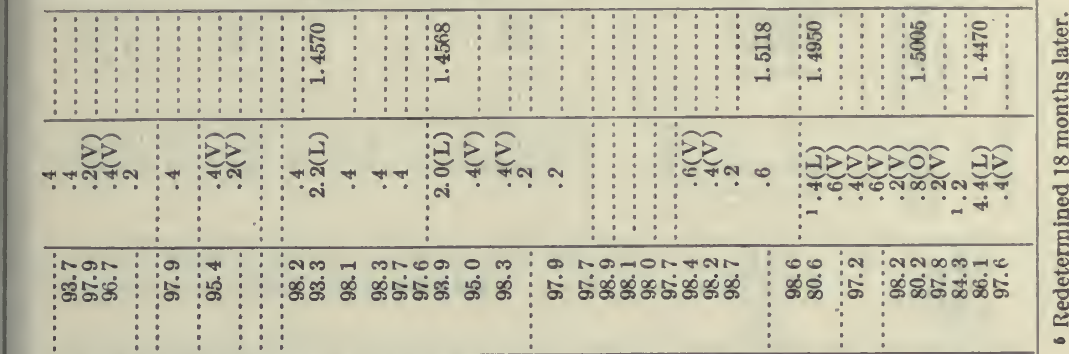

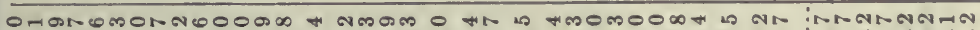

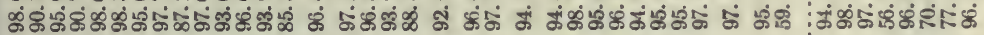

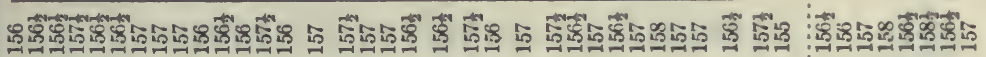

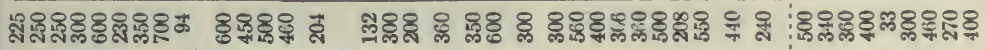
$\sum^{2}$

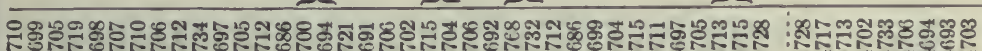

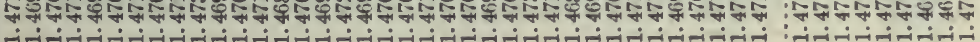
-

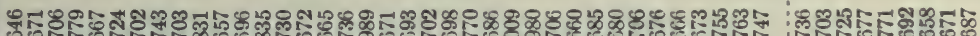
\$

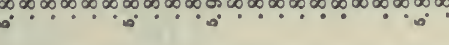

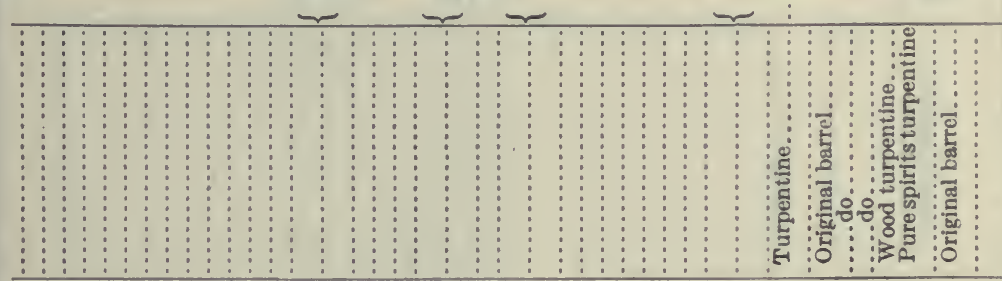

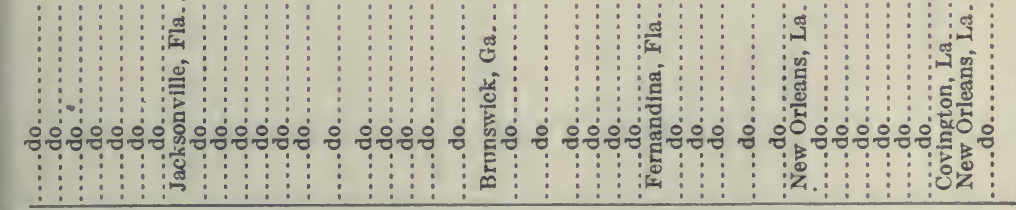




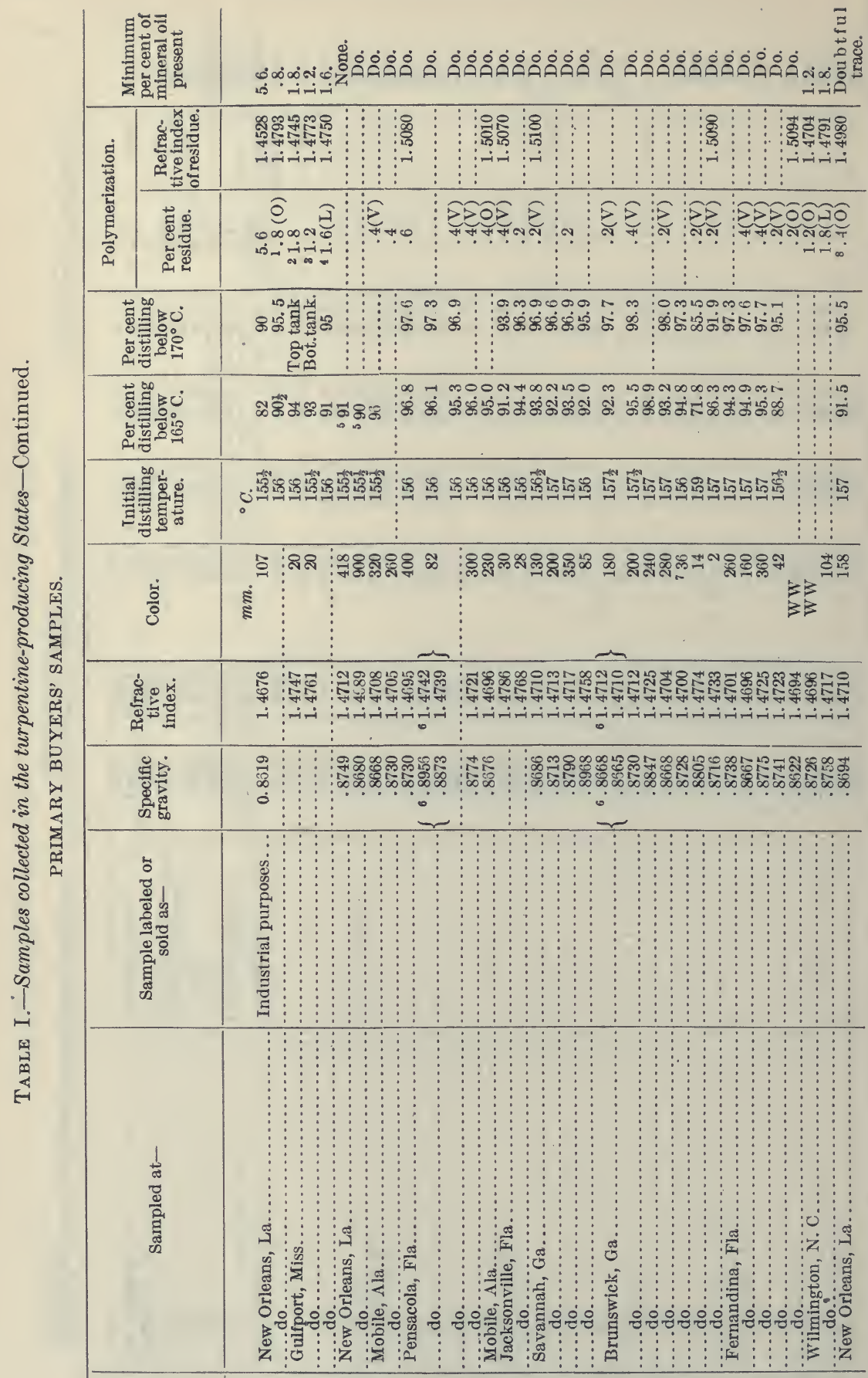

ㄴ.1.

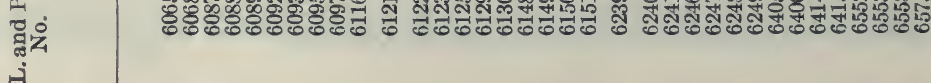




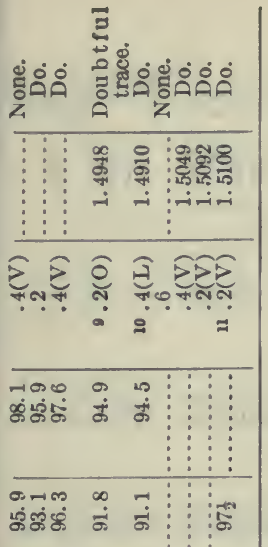

๗ळं में

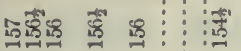

চ్ఞ :

ส్ㅠㅜㅝ

मीं में

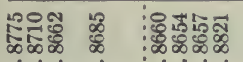

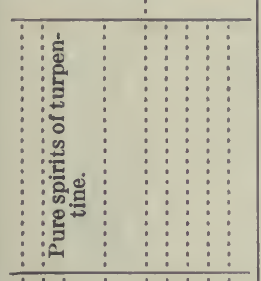

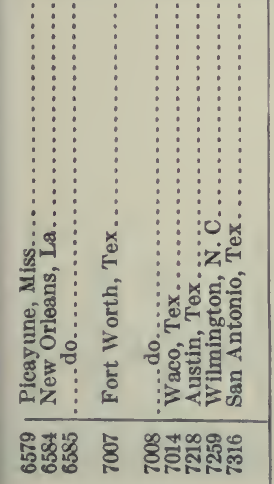

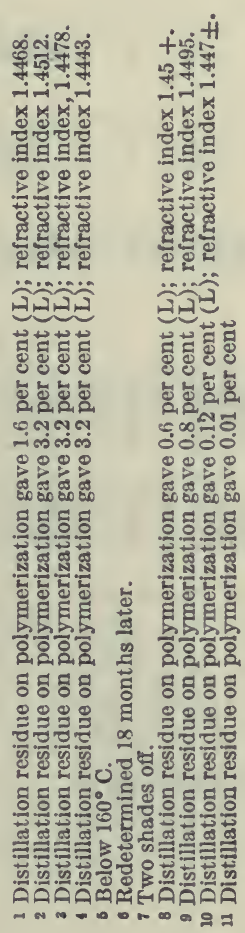




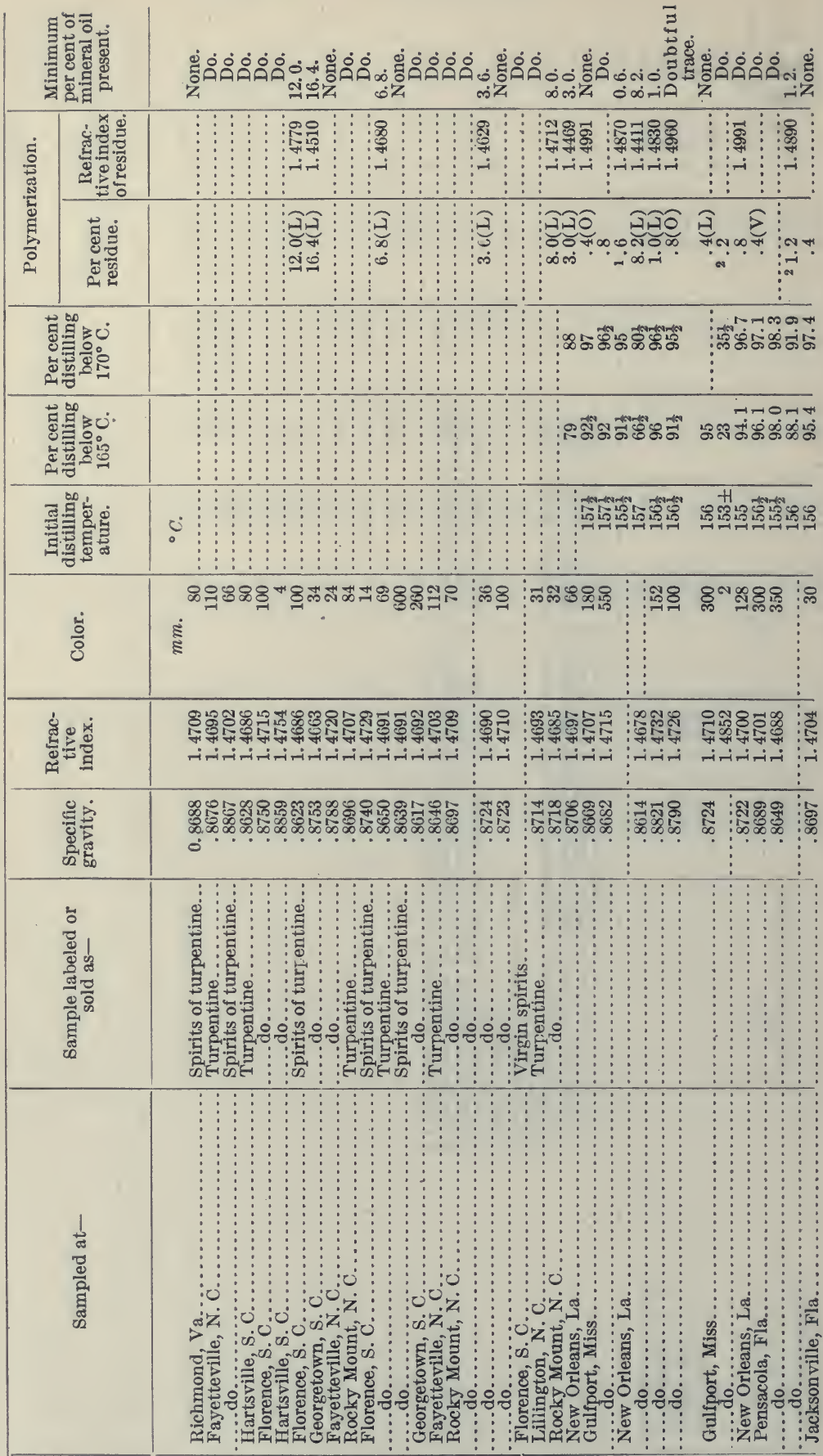




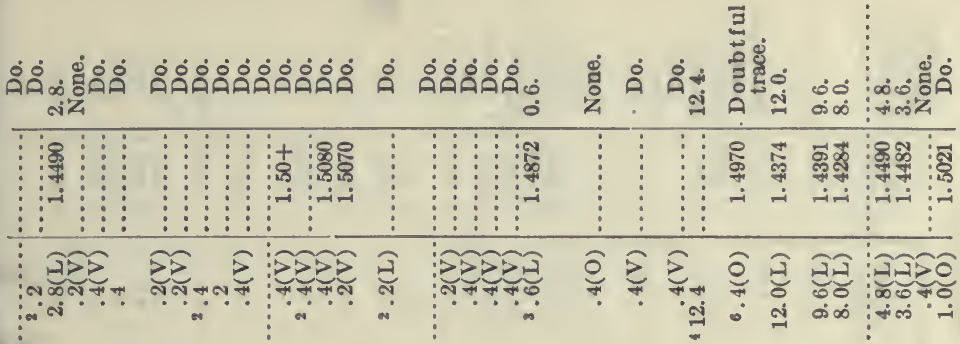

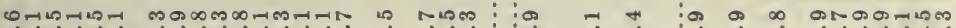

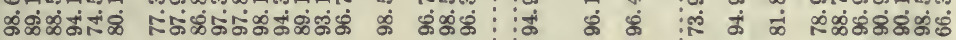

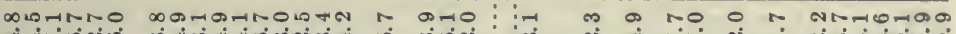

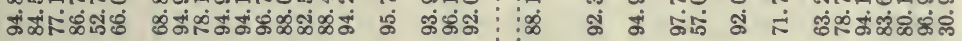

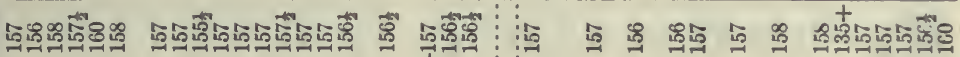
㟧

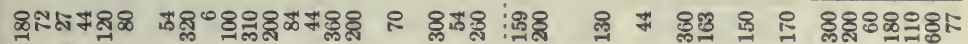

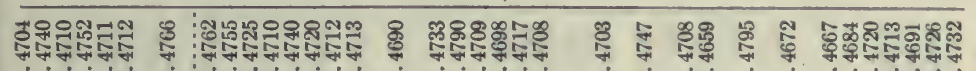

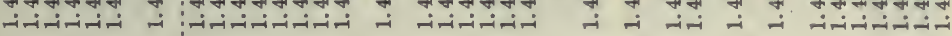

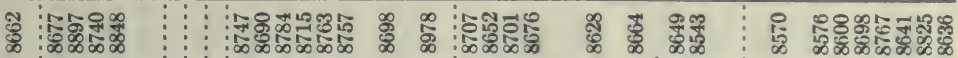

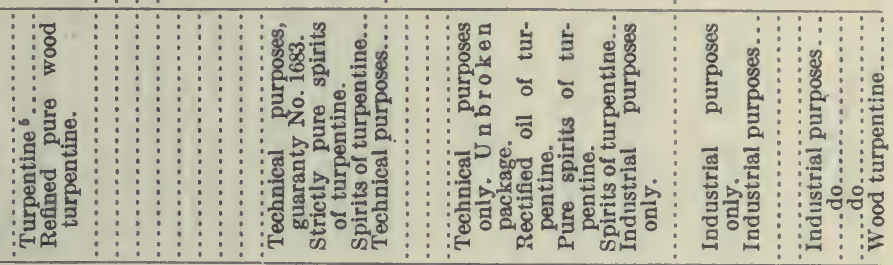
에. 10 00

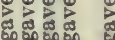
동명명

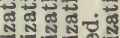

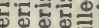

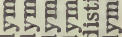
응응

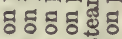
ฐึ?

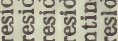

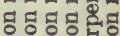
ㄴ.

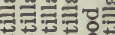
ज्ञ aอด

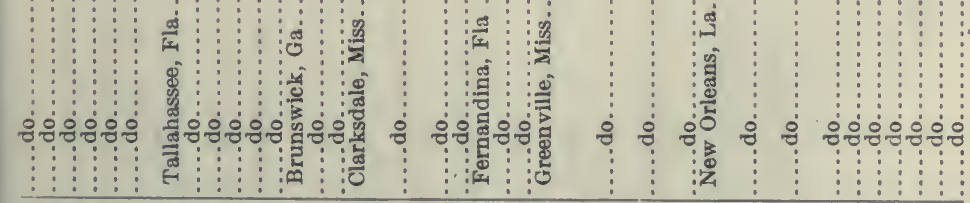

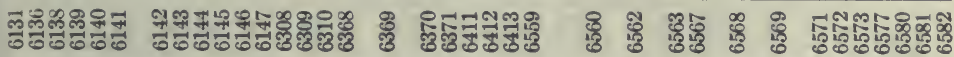




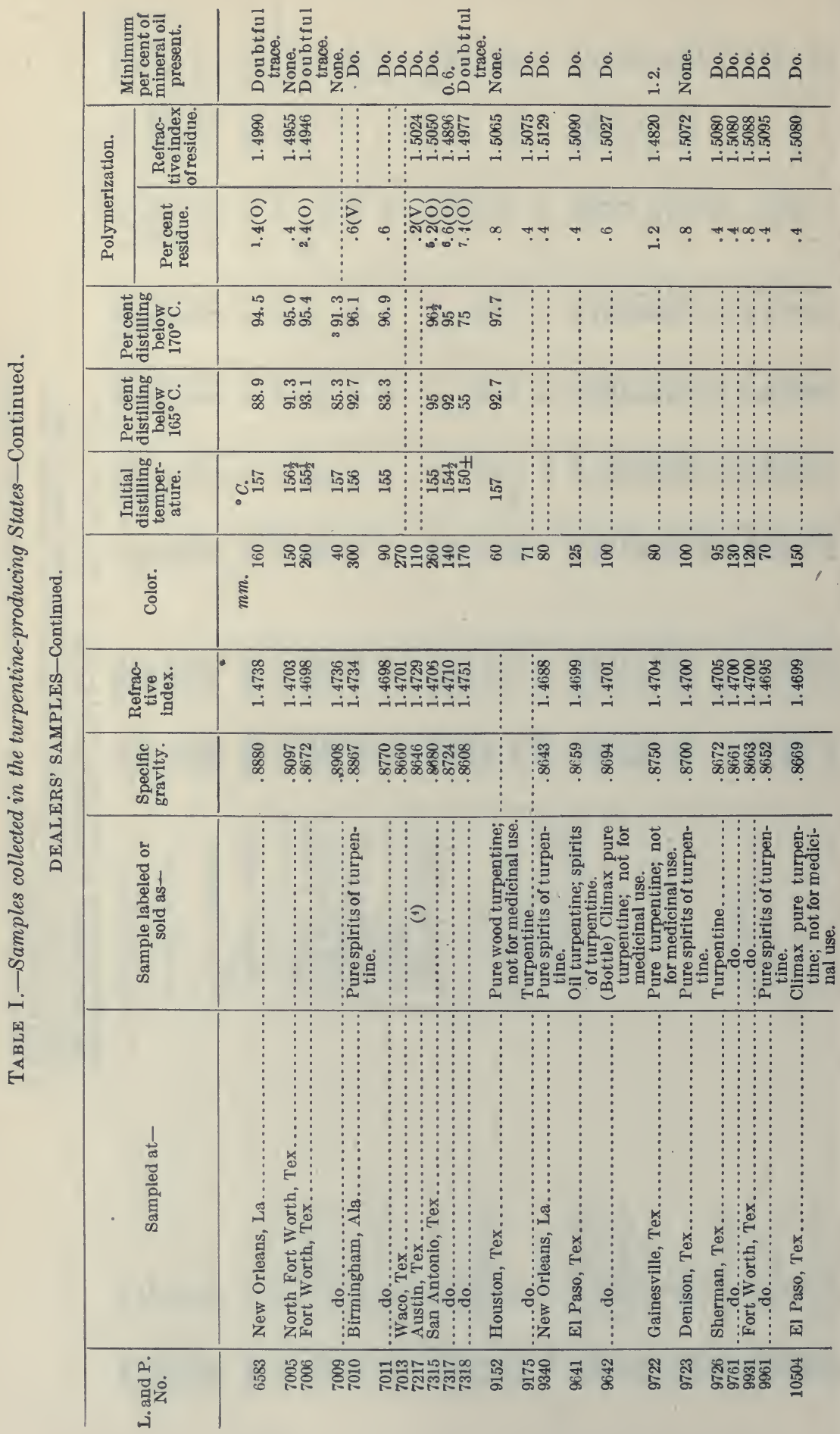




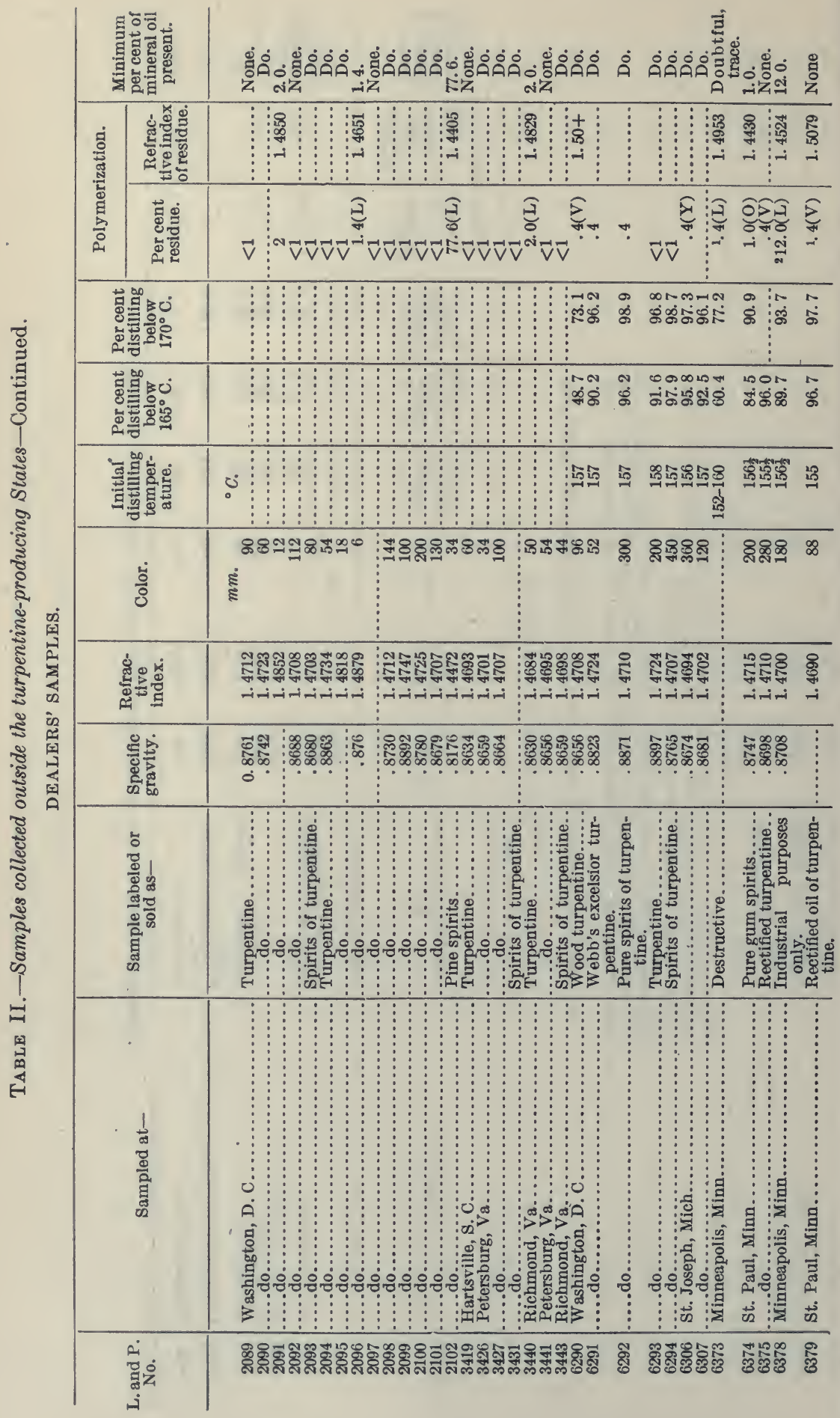




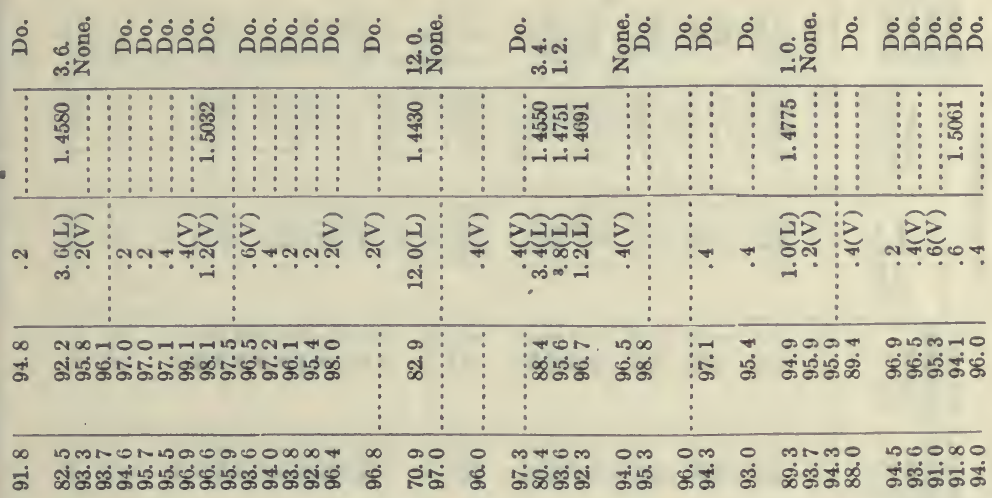

霆

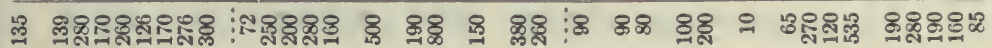

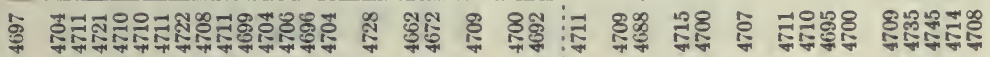
要, i

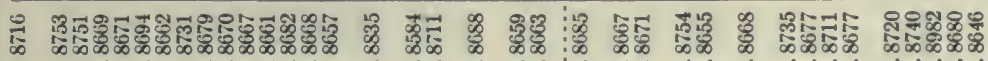
$0 . \overline{0}$ 90

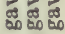
믕뮹융

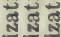

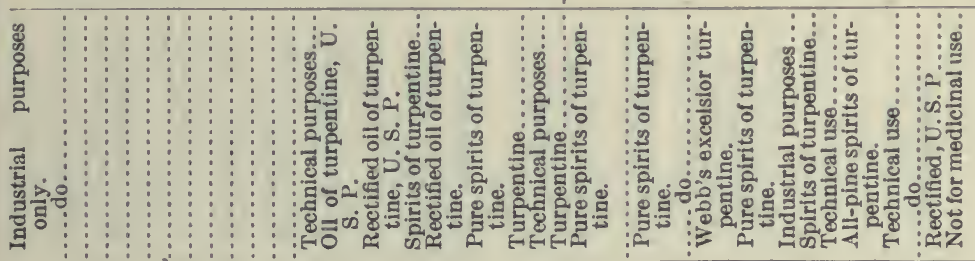

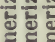
菲

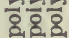
동동

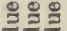

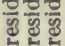
5.

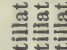

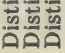

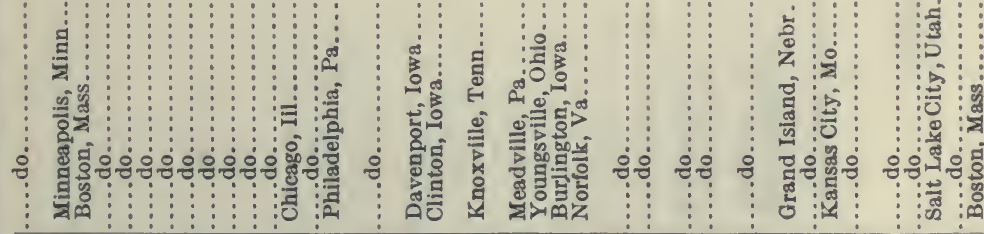

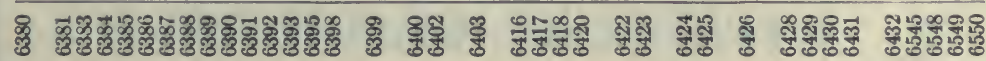




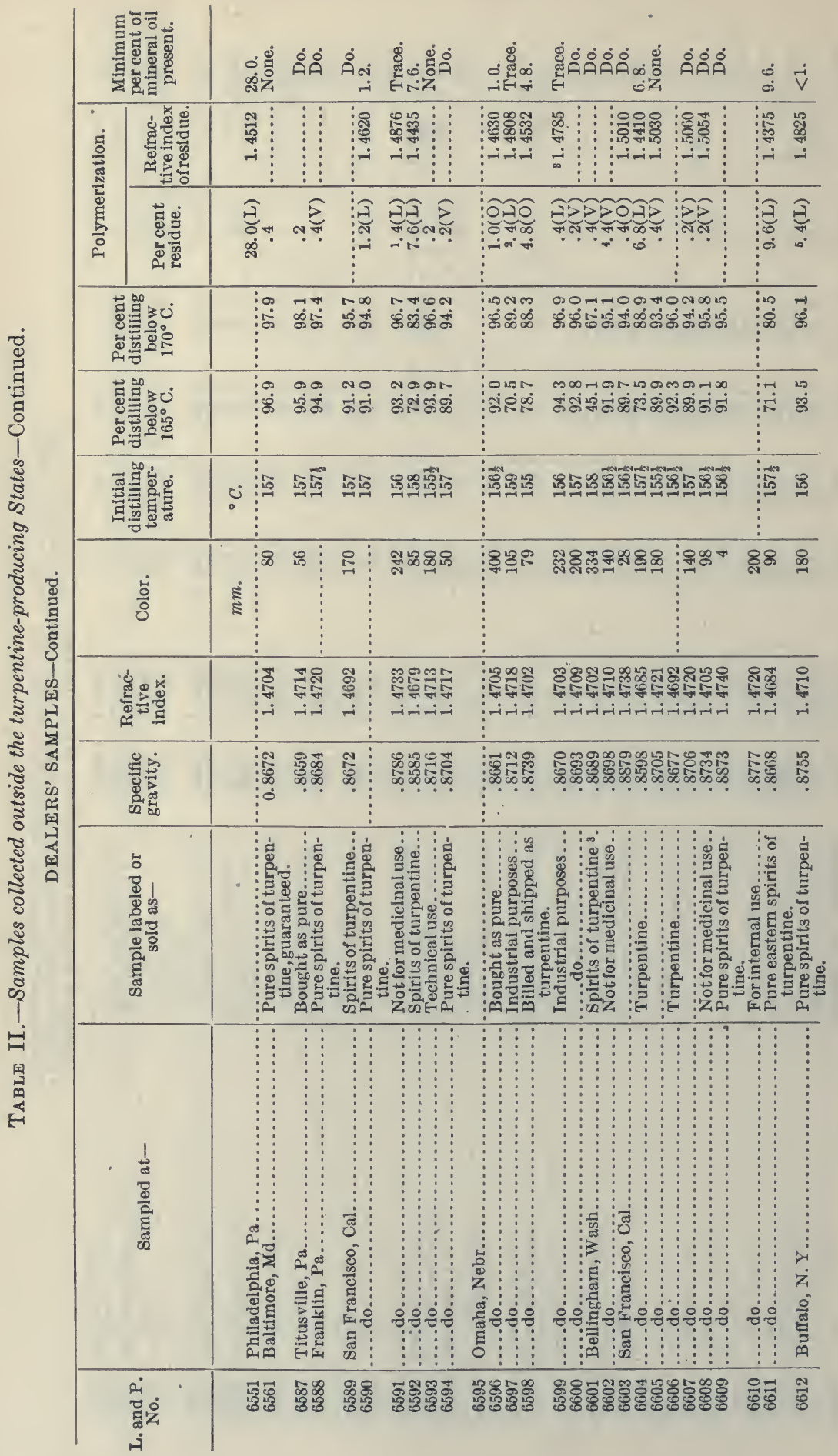




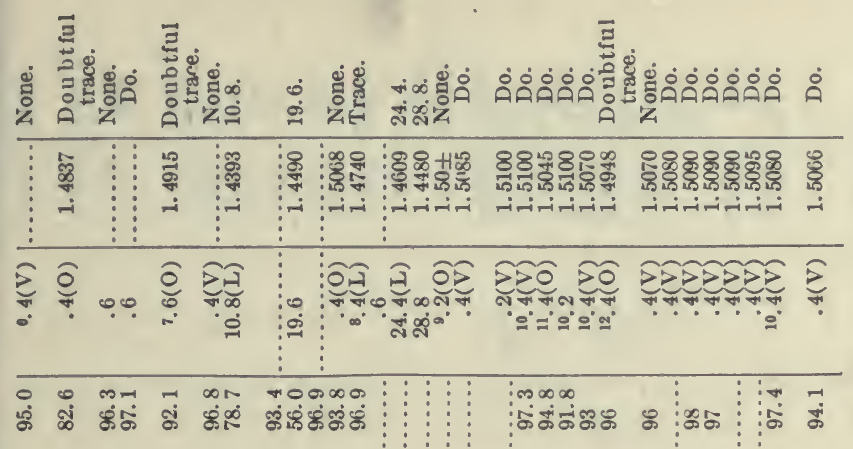

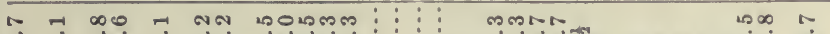

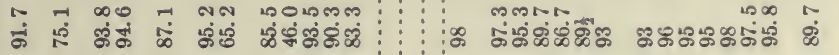

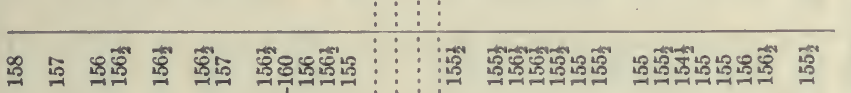
สู

\section{댄} 必

\begin{tabular}{|c|c|c|c|c|c|c|}
\hline 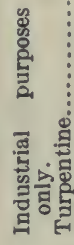 & 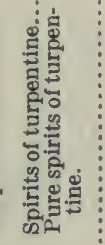 & 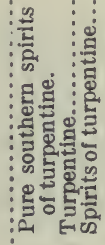 & 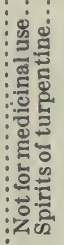 & 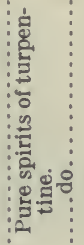 & 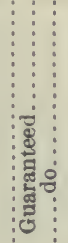 & 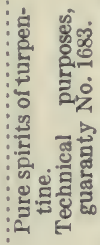 \\
\hline
\end{tabular}

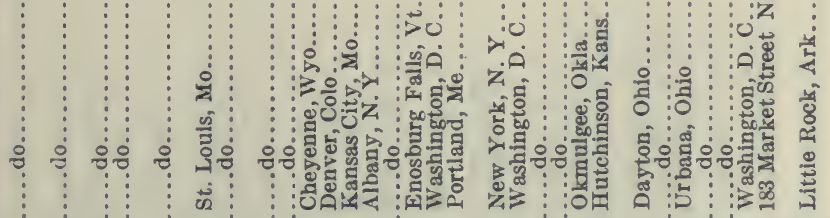

产雾 


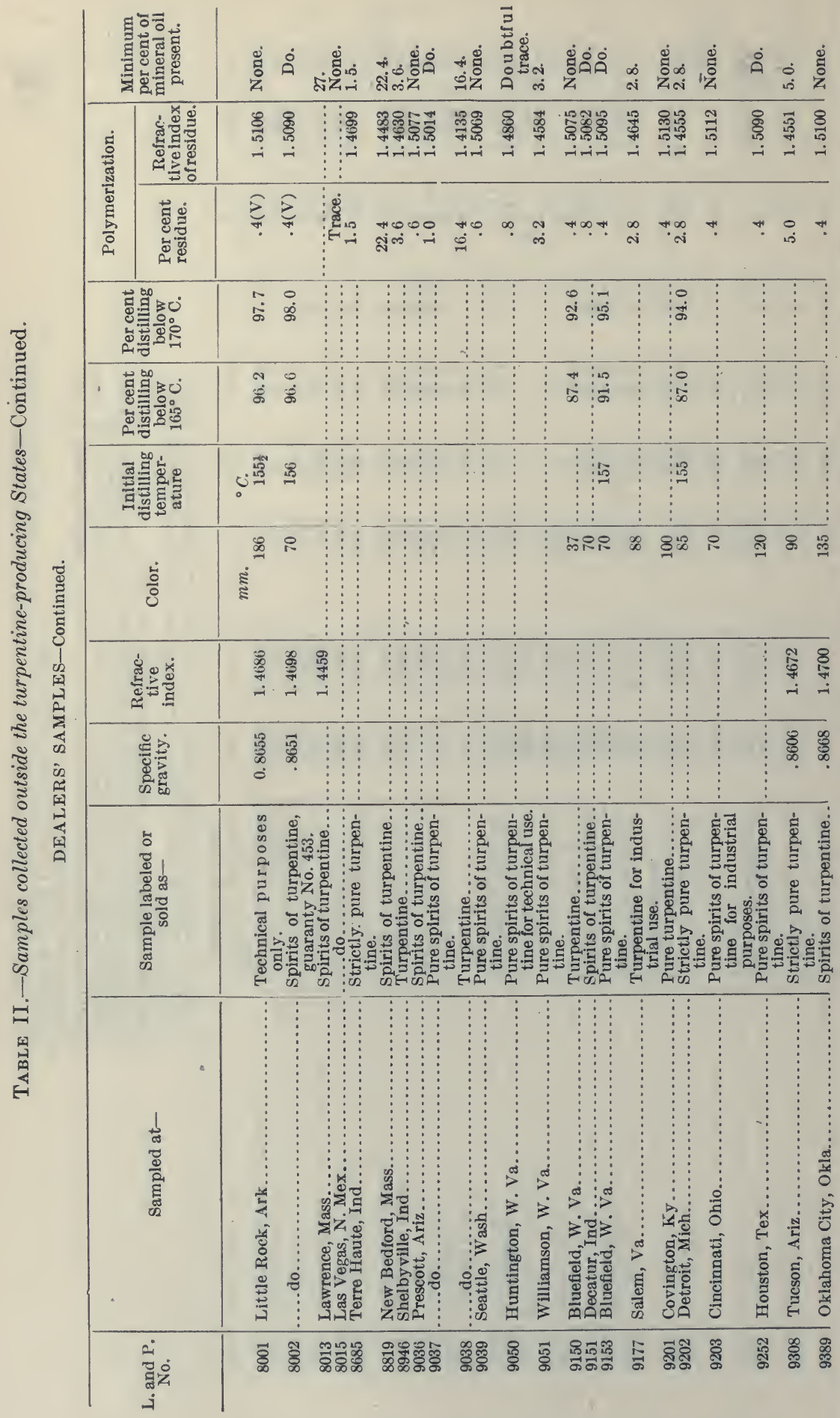




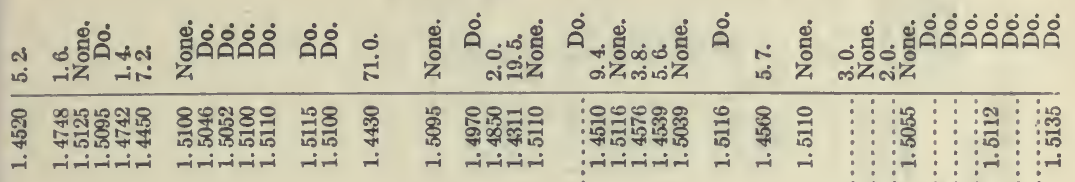

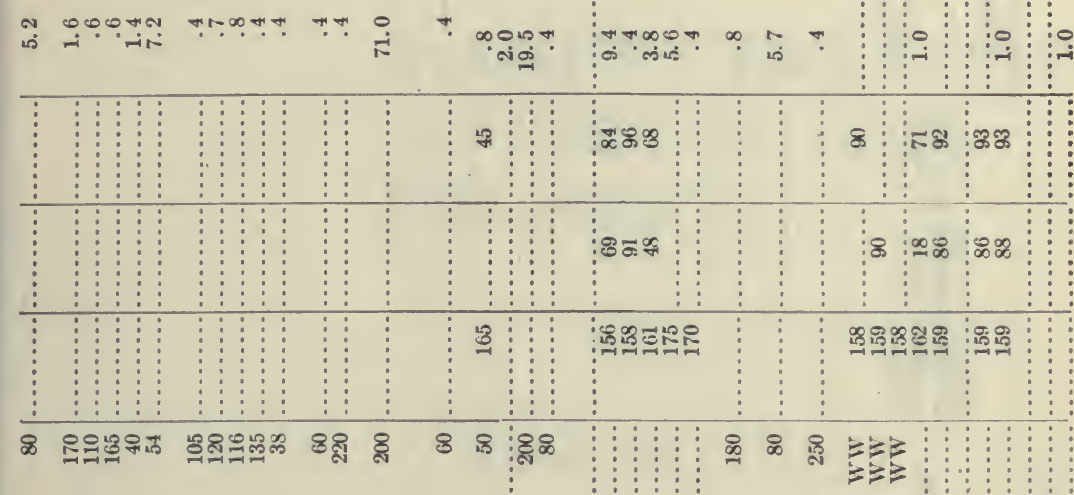

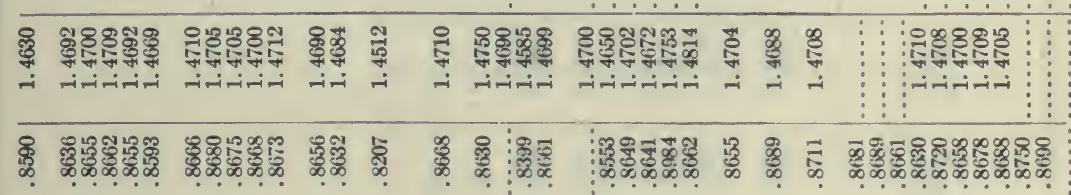
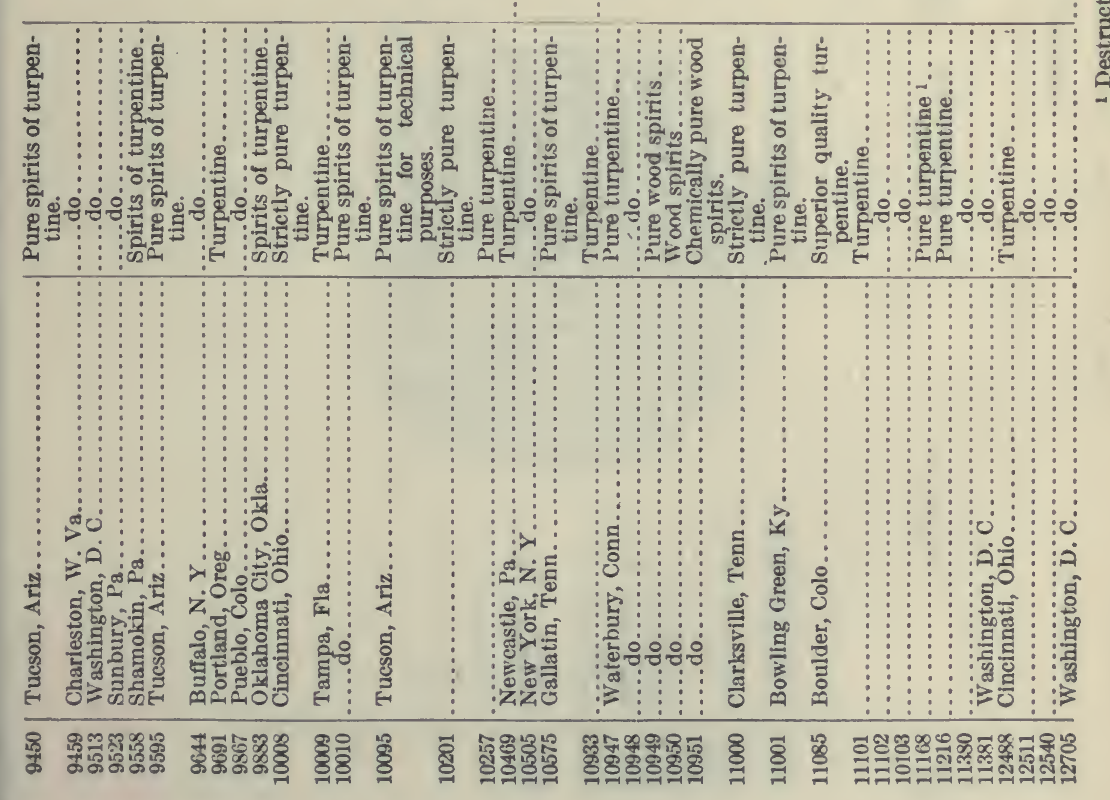


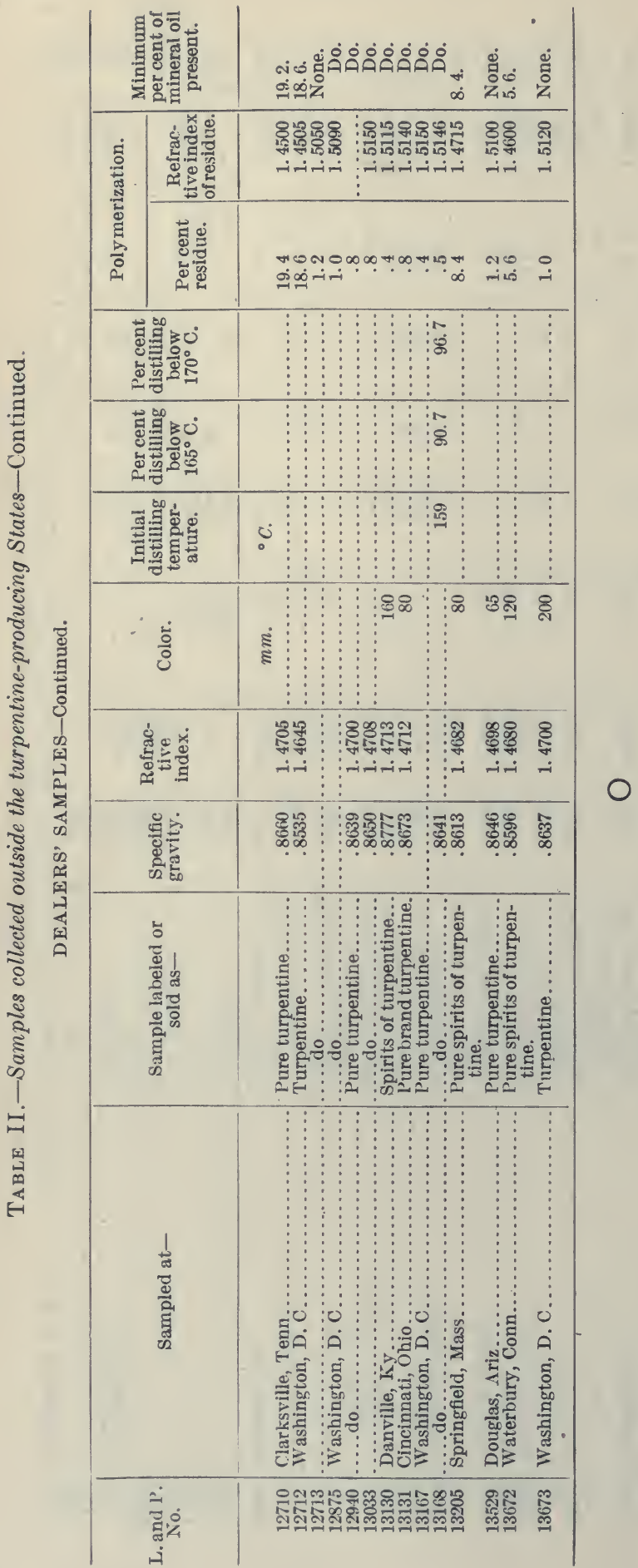


YO 18295
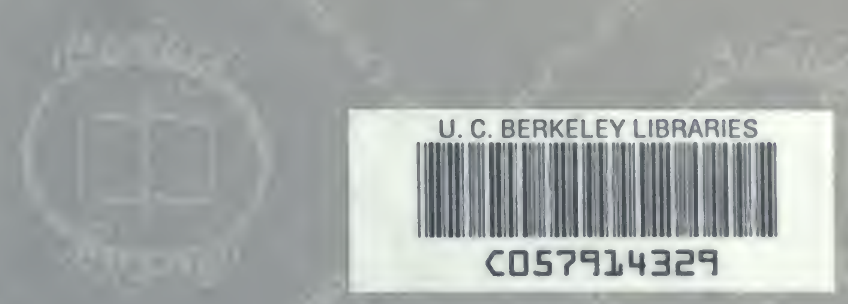
